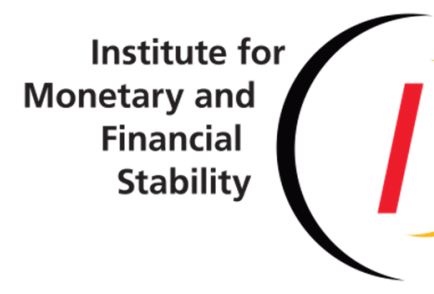

MICHAEL D. BAUER, ERIC T. SWANSON

The Fed's Response to Economic News Explains the "Fed Information Effect"

Institute for Monetary and Financial Stability

GOETHE UNIVERSITY FRANKFURT 
This Working Paper is issued under the auspices of the Institute for Monetary and Financial Stability (IMFS). Any opinions expressed here are those of the author(s) and not those of the IMFS. Research disseminated by the IMFS may include views on policy, but the IMFS itself takes no institutional policy positions.

The IMFS aims at raising public awareness of the importance of monetary and financial stability. Its main objective is the implementation of the "Project Monetary and Financial Stability" that is supported by the Foundation of Monetary and Financial Stability. The foundation was established on January 1, 2002 by federal law. Its endowment funds come from the sale of 1 DM gold coins in 2001 that were issued at the occasion of the euro cash introduction in memory of the D-Mark.

The IMFS Working Papers often represent preliminary or incomplete work, circulated to encourage discussion and comment. Citation and use of such a paper should take account of its provisional character.

\section{Institute for Monetary and Financial Stability}

Goethe University Frankfurt

House of Finance

Theodor-W.-Adorno-Platz 3

D-60629 Frankfurt am Main

www.imfs-frankfurt.de | info@imfs-frankfurt.de 


\title{
The Fed's Response to Economic News Explains the "Fed Information Effect"*
}

\author{
Michael D. Bauer \\ Universität Hamburg and CESifo
}

\author{
Eric T. Swanson \\ Univ. of California, Irvine and NBER
}

July 28, 2020

\begin{abstract}
High-frequency changes in interest rates around FOMC announcements are a standard method of measuring monetary policy shocks. However, some recent studies have documented puzzling effects of these shocks on private-sector forecasts of GDP, unemployment, or inflation that are opposite in sign to what standard macroeconomic models would predict. This evidence has been viewed as supportive of a "Fed information effect" channel of monetary policy, whereby an FOMC tightening (easing) communicates that the economy is stronger (weaker) than the public had expected. We show that these empirical results are also consistent with a "Fed response to news" channel, in which incoming, publicly available economic news causes both the Fed to change monetary policy and the private sector to revise its forecasts. We provide substantial new evidence that distinguishes between these two channels and strongly favors the latter; for example, (i) regressions that include the previously omitted public macroeconomic news, (ii) high-frequency stock market responses to Fed announcements, and (iii) a new survey that we conduct of individual Blue Chip forecasters all indicate that the Fed and private sector are simply responding to the same public news, and that there is little if any role for a "Fed information effect."
\end{abstract}

JEL Classifications: E43, E52, E58

Keywords: Federal Reserve, forecasts, survey, Blue Chip, Delphic forward guidance

\footnotetext{
${ }^{*}$ We thank the Blue Chip forecasters who answered our survey, Sophia Friesenhahn and Benjamin Shapiro for excellent research assistance, and David Lucca, Kurt Lunsford, Mirela Miescu, Silvia Miranda-Agrippino, Pascal Paul, Giovanni Ricco, and seminar participants at the Bundesbank, the Federal Reserve Banks of Cleveland, Kansas City, and New York, the Federal Reserve Board, LMU Munich, NBER Summer Institute, Universität Hamburg, and UNSW Continuing Education in Macroeconometrics Conference for helpful discussions, comments, and suggestions. Any errors or omissions are solely those of the authors. Bauer: michael.bauer@uni-hamburg.de, www.michaeldbauer.com. Swanson: eric.swanson@uci.edu, www. ericswanson. org.
} 


\section{Introduction}

When the Federal Reserve surprises markets with a monetary policy announcement, is that surprise an exogenous "shock", as is typically assumed in the monetary policy VAR literature (e.g., Christiano, Eichenbaum and Evans, 1996; Cochrane and Piazzesi, 2002; Faust, Swanson and Wright, 2004b)? Or is the surprise due to other factors, such as a revision in investor beliefs about the state of the economy, as argued by recent "Fed information effect" studies such as Romer and Romer (2000), Campbell, Evans, Fisher and Justiniano (2012), and Nakamura and Steinsson (2018)? The answers to these questions have important implications for empirical work on the financial and macroeconomic effects of monetary policy. In this paper, we present new evidence that challenges the empirical relevance of a Fed information effect and instead supports an alternative explanation of the empirical evidence in Campbell et al. (2012) and Nakamura and Steinsson (2018), which we call the "Fed response to news" channel.

A simple monetary policy reaction function highlights the difference between the Fed information effect and Fed response to news channels. Let

$$
i_{t}=f\left(X_{t}\right)+\varepsilon_{t},
$$

where $i_{t}$ denotes the monetary policy instrument at time $t, X_{t}$ is a vector describing the state of the economy, the function $f$ describes how the Fed sets policy as a function of the state $X_{t}$, and $\varepsilon_{t}$ is a pure monetary policy "shock", or exogenous random deviation from the Fed's normal policy rule $f$. When the Fed sets a value of $i_{t}$ that differs from the private sector's ex ante expectation, $E_{t-\delta} i_{t}$, where $\delta$ is some small time interval, then there are three possible sources of that surprise: 1) an exogenous monetary policy shock $\varepsilon_{t} ; 2$ ) a Fed information effect, in which the Fed's observation of $X_{t}$ differs from the private sector's ex ante estimate $\hat{X}_{t \mid t-\delta}$, conditional on information at time $t-\delta$; or 3 ) a difference between the Fed's actual policy response function $f$ and the the private sector's ex ante estimate of that function, $\hat{f}_{t-\delta}$. It is this last channel that causes the Fed's response to the economy and publicly available economic news to differ from the private sector's expectation of that response, and drives the Fed response to news channel, as we discuss in more detail below. Campbell et al. (2012) and Nakamura and Steinsson (2018) devote much attention to distinguishing between channels 1 and 2, above, essentially assuming that the Fed's monetary policy reaction function is known, 
Figure 1: Blue Chip GDP Forecast Revisions and FOMC Monetary Policy Surprises

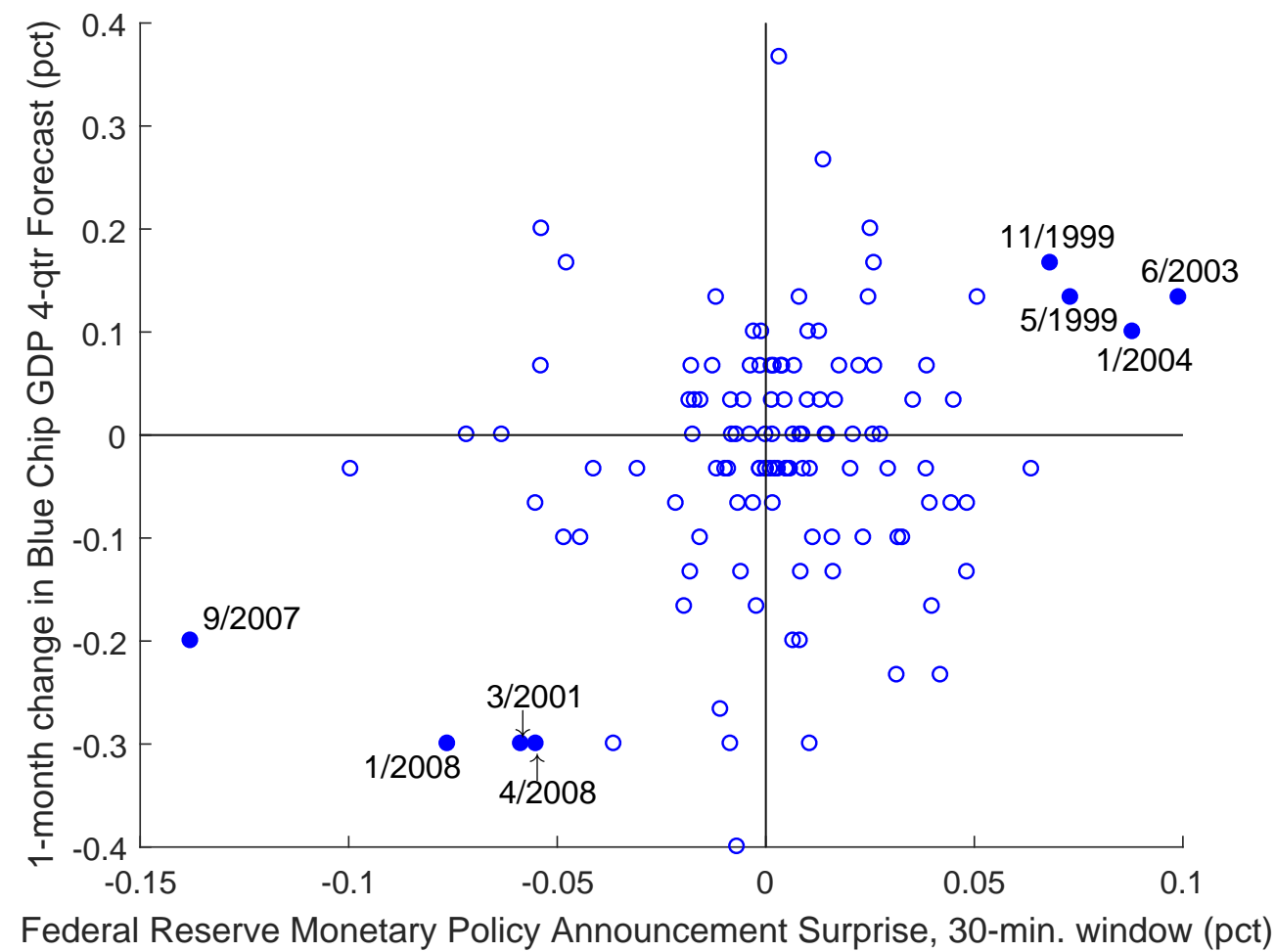

Change in Blue Chip consensus forecast for real GDP from one month to the next, plotted against the 30minute change in short-term interest rates around FOMC announcements, from January 1995 to March 2014, excluding July 2008 to June 2009. Each circle represents an FOMC announcement; the eight solid circles denote the most influential observations in the relationship and are labeled with the month and year in which they occurred. Negative observations occurred when the economy was weakening and positive observations when the economy was strengthening. See text for details.

$\hat{f}_{t-\delta}=f$. We relax this assumption and show that the empirical evidence in Campbell et al. (2012) and Nakamura and Steinsson (2018) is also consistent with channel 3, above, in which the Fed is responding to publicly available economic news, but by more than the private sector expected.

Figure 1 summarizes the main evidence supporting the Fed information effect in Nakamura and Steinsson (2018). Each circle in the figure corresponds to a Federal Reserve Federal Open Market Committee (FOMC) announcement between January 1995 and March 2014. ${ }^{1}$ The

\footnotetext{
${ }^{1}$ To match Nakamura and Steinsson (2018), we use exactly the same sample in Figure 1 that they do: we begin the sample in 1995 and end it in March 2014, and we exclude unscheduled FOMC announcements, all FOMC announcements from July 2008 through June 2009, and any FOMC announcement that occurred in the first 7 days of the month (to ensure the announcement post-dates the Blue Chip forecast). We measure the change in short-term interest rates in exactly the same way Nakamura and Seinsson do. Figure 1 thus replicates Figure II from Nakamura and Steinsson, except that they group the data into bins while we plot the data directly and highlight the most influential observations.
} 
change in short-term interest rates in a 30-minute window around each announcement is plotted on the horizontal axis, while the change in the Blue Chip consensus GDP forecast for the next four quarters is plotted on the vertical axis. Because the Blue Chip survey is conducted only once per month (at the beginning of each month), the change in Blue Chip GDP forecasts on the vertical axis includes Blue Chip forecasters' revisions over the entire month in which the FOMC announcement was made.

If FOMC announcements were exogenous shocks to monetary policy (channel 1, above), then standard macroeconomic theory and VARs would predict a negative relationship in Figure 1: exogenously tighter monetary policy would imply lower GDP over the subsequent four quarters. Instead, there is a statistically significant positive relationship in the figure (slope 0.92, $t$-statistic 2.85). Nakamura and Steinsson (2018) argue that this surprising empirical result is evidence of a Fed information effect (channel 2, above): that is, the Fed observes a value for $X_{t}$ that is substantially stronger than the private sector's estimate $E_{t-\delta} X_{t}$ and tightens interest rates in response; the private sector sees this interest rate change and infers from it that the economy must be stronger than they thought, leading them to revise their GDP forecast upward.

However, the evidence in Figure 1 is also consistent with an alternative explanation, the "Fed response to news" channel that we propose in this paper. The solid circles in Figure 1 denote the eight most influential observations underlying the relationship in the figure. The four observations at the bottom-left all correspond to months in which the U.S. economy was clearly weakening: March 2001, September 2007, January 2008, and April 2008. A plausible explanation for these observations is that the clearly deteriorating economy caused both the Fed to lower interest rates (by more than financial markets expected) and the Blue Chip forecasters to revise their GDP forecasts downward. Similarly, the four observations at the top-right of the figure all correspond to months in which the U.S. economy was in an expansion: May 1999, November 1999, June 2003, and January 2004. Again, it seems plausible that the strengthening economy caused both the Fed to raise interest rates and Blue Chip forecasters to revise their GDP forecasts upward. ${ }^{2}$ This is the essence of the Fed response to news channel that we propose here.

\footnotetext{
${ }^{2}$ In June 2003, the Fed lowered interest rates, but by less than the markets had expected, which resulted in a monetary policy tightening surprise. The economy was in an expansion and the news about output had been good, but the unemployment rate had not yet fallen, leading the Fed to cut rates slightly.
} 
To distinguish between the Fed information effect and the Fed response to news channels, we present substantial new empirical evidence, all of which strongly favors the latter. First, in Section 2, we show that Blue Chip survey regressions along the lines of Campbell et al. (2012) and Nakamura and Steinsson (2018) are sensitive to the sample period and the variable being forecast (i.e., GDP, unemployment, or inflation). If these regression results are truly due to a Fed information effect, it suggests that the information content of FOMC announcements would have to be changing over time, sometimes conveying information about GDP but not unemployment or inflation, other times conveying information about unemployment but not GDP or inflation, and so on. Instead, if these regression results are driven by the Fed's response to publicly available economic news, then we would expect the coefficients to vary over time in line with the news that was released.

In Section 3, we show that economic news released in the days between the last Blue Chip survey and the FOMC announcement is an important omitted variable in these survey regressions. For example, the employment report in a given month is a strong predictor of both the Blue Chip forecast revision and the FOMC monetary policy announcement surprise later that month. Controlling for this economic news renders the statistical relationship between policy surprises and Blue Chip forecast revisions statistically insignificant and reverses its sign back to what would be predicted by standard macroeconomic models. Thus, we show that the positive relationship in Figure 1 is in fact entirely driven by the omitted economic news variable, in line with the Fed response to news channel.

In Section 4, we analyze high-frequency, 30-minute responses of the stock market to FOMC announcements. Several authors (e.g., Jarocinski and Karadi, 2020; Cieslak and Schrimpf, 2019) have argued that the stock market responds positively to a monetary policy tightening surprise when a substantial information effect is present. We show that Federal Reserve monetary policy surprises have a strong, highly statistically significant negative effect on stock prices on average, and that this effect is even more negative for the most influential observations in the Blue Chip regressions - for example, every one of the four highlighted observations in the upper-right corner of Figure 1 led to large decreases in the S\&P 500 in the 30-minute windows surrounding those announcements. These high-frequency stock market responses pose a significant challenge to the Fed information effect story, but we show below that they are consistent with the Fed response to news channel. 
In Section 5, we present new evidence on how individual Blue Chip forecasters revise their forecasts on the day of an FOMC announcement, rather than over the one-month window surrounding the announcement. For example, we have high-frequency, daily "GDP tracking" estimates from one award-winning Blue Chip forecaster, Macroeconomic Advisers, that shows that they have never revised their current-quarter or next-quarter GDP forecast in response to an FOMC announcement going back to at least 2002. In contrast, Macroeconomic Advisers revises their GDP tracking forecasts in response to many other macroeconomic announcements over the course of each month, such as the employment report, retail sales, CPI, etc. This suggests that the Fed information effect is very small, at least for this one award-winning Blue Chip forecaster. We follow up this analysis with our own direct survey of all 52 individual forecasters in the Blue Chip panel, and ask them directly if they revise their GDP, unemployment, and/or inflation forecasts in response to FOMC announcements, and if so, in which direction. According to our survey, Blue Chip forecasters generally either do not revise those forecasts in response to FOMC announcements, or they revise them in the traditional direction, with a hawkish monetary policy surprise causing them to revise their GDP and inflation forecasts downward and their unemployment forecasts upward. This is direct evidence, from the Blue Chip survey participants themselves, that there is little or no Fed information effect. In contrast, our Fed response to news channel is consistent with all of these observations.

In Section 6, we conduct a detailed comparison of Blue Chip and Federal Reserve internal ("Greenbook") forecasts of GDP, unemployment, and inflation. Many authors, such as Romer and Romer (2000), argue that a Fed information effect exists because the Fed's economic forecasts are significantly better than those of the private sector. In fact, we show that the Fed's internal forecasts are very similar to the Blue Chip consensus forecasts, and that neither forecast has a statistically significant advantage over the other.

Finally, in Section 7, we present a simple model of private sector learning about the Fed's monetary policy rule that illustrates the Fed response to news channel and is consistent with all of our empirical findings. Using the model as a benchmark, we show that standard, highfrequency monetary policy surprises can be used in high-frequency regressions to estimate the effects of monetary policy on the yield curve and other asset prices in the usual way, without any correction or adjustment. However, for high-frequency identification of a monetary policy VAR, as in Cochrane and Piazzesi (2002), Faust et al. (2004b), and Gertler and Karadi (2015), 
correcting the high-frequency monetary policy surprises for the Fed response to news channel may in some cases be necessary.

Section 8 concludes. Two Appendices provide additional details of our survey of Blue Chip forecasters and additional regression results and robustness checks.

\subsection{Related Literature}

Theoretical models of monetary policy have allowed for the possibility that the central bank possesses asymmetric information about the economy since at least the 1970s (e.g., Sargent and Wallace, 1975; Barro, 1976; Barro and Gordon, 1983), but the first paper to argue for the empirical relevance of the Fed information effect is Romer and Romer (2000). They found that the Fed has substantial information about future inflation that private sector forecasters do not have, and that the Fed's interest rate changes could be used to infer that information. ${ }^{3}$

Faust, Swanson and Wright (2004a) showed that the Fed's monetary policy announcements cannot be used to improve private-sector forecasts of upcoming macroeconomic data releases, such as GDP, retail sales, CPI, etc. They also showed that the private sector does not seem to revise its forecasts of these releases in response to FOMC announcements, even though it does revise those forecasts in response to other major macroeconomic data releases, such as the employment report. They conclude that there is little or no evidence of a Fed information effect in the data. They also show that the Romer and Romer (2000) results for inflation are entirely due to the Volcker disinflation in the early 1980s; excluding that one episode, the Fed's inflation forecasts are no better than those of the private sector.

Campbell et al. (2012) study how the Fed's monetary policy announcements affect Blue Chip forecasts of unemployment and inflation. Consistent with Faust et al. (2004a) and contrary to Romer and Romer (2000), they find no evidence that Fed announcements contain significant information about inflation. However, Campbell et al. find that monetary policy tightenings are associated with a significant downward revision in Blue Chip forecasts of unemployment, which they conclude is due to a Fed information effect. They introduce the

\footnotetext{
${ }^{3}$ Romer and Romer (2000) appealed to this Fed information effect to explain why long-term U.S. Treasury yields seemed to rise in response to federal funds rate changes. However, Gürkaynak, Sack and Swanson (2005a), using a futures-based measure of federal funds rate surprises, showed that far-ahead forward U.S. Treasury yields actually fall in response to FOMC tightenings. Thus, an information effect is not needed to explain the response of long-term Treasury yields to FOMC announcements.
} 
term "Delphic forward guidance" to refer to situations in which forward guidance by the FOMC conveys information about the future evolution of the economy to the private sector.

Nakamura and Steinsson (2018) study how Fed monetary policy announcements affect Blue Chip forecasts of real GDP. They find that monetary policy tightenings are associated with a significant upward revision in Blue Chip forecasts of real GDP, and like Campbell et al. (2012), conclude that a Fed information effect is present. In Section 2, below, we explore both the Campbell et al. and Nakamura-Steinsson results in more detail and show that they are sensitive to sample period and the variable being forecast. For example, using Nakamura and Steinsson's sample and methods, there is no significant information effect for unemployment (contrary to Campbell et al.) or for inflation (contrary to Romer and Romer, 2000).

Lunsford (2019) performs a detailed analysis of the Fed's forward guidance announcements from February 2000 to May 2006, and finds evidence of a Fed information effect in the period from February 2000 to August 2003, but not afterward. (Lunsford does not consider the period before 2000 or after May 2006 due to changes in FOMC statements outside this window.) Like Lunsford, we find no evidence of an information effect in the period after 2003; unlike Lunsford, we attribute the appearance of a "Fed information effect" from 2000-2003 to the Fed's response to the deteriorating economy in early 2001 and the improving economy in mid-2003.

Jarocinski and Karadi (2020) decompose monetary policy surprises in the U.S. and euro area into "pure monetary" shocks and "information" shocks, depending on whether stock prices move in the opposite direction or same direction as interest rates, respectively. ${ }^{4}$ They estimate a Bayesian VAR using their high-frequency monetary and information shocks as instruments, and find that pure monetary shocks cause future GDP to decline, while pure information shocks cause future GDP to increase. In our analysis below, we also use stock market responses to FOMC announcements to assess whether they have a significant information component, but we find little or no evidence of an information effect (for the U.S.) ${ }^{5}$

Finally, Miranda-Agrippino (2017), Cieslak (2018), and Karnaukh (2019) find that FOMC announcement surprises are predictable using macroeconomic data that are publicly available

\footnotetext{
${ }^{4}$ See also Cieslak and Schrimpf (2019), who similarly classify monetary policy surprises according to the minute-by-minute covariance of stock price changes and bond yield changes in a narrow window of time around each announcement.

${ }^{5}$ Figure 1 of Jarocinski and Karadi (2020) reports very few observations in their sample that qualify as significant information shocks. Our results are generally consistent with this fact.
} 
prior to the announcement. Miranda-Agrippino (2017) interprets this predictability as a risk premium that compensates investors for holding interest rate risk around FOMC announcements. However, Piazzesi and Swanson (2008) estimate that this risk premium is relatively small, and Cieslak (2018) argues extensively that this predictability is not a risk premium, but is instead due to markets having underestimated the Fed's responsiveness to the state of the economy. Cieslak's explanation is essentially the same as our "Fed response to news" channel, and is consistent with all of the new empirical evidence we present, below.

\section{The "Fed Information Effect"}

We begin by replicating and extending the empirical evidence of a "Fed information effect" presented by Romer and Romer (2000), Campbell et al. (2012), and Nakamura and Steinsson (2018), based on the response of Blue Chip survey forecasts to high-frequency FOMC monetary policy surprises. We investigate the robustness of this evidence, and we present our alternative explanation - the "Fed response to news" channel-based on the Fed's response to publicly available macroeconomic news.

\subsection{Data: Blue Chip Forecasts and Monetary Policy Surprises}

The Blue Chip Economic Indicators newsletter has conducted a survey of professional forecasters once per month, over the first three business days of each month, since $1976 .{ }^{6}$ The forecasting teams at approximately 50 financial institutions, major corporations, and economic forecasting firms are surveyed about their predictions for a variety of macroeconomic indicators for each quarter over the current and next calendar years. Thus, the maximal forecast horizon ranges from four quarters (when the survey is conducted in the last quarter of a calendar year) to seven quarters (when it is conducted in the first quarter). The survey covers real U.S. Gross Domestic Product (GDP) growth, the unemployment rate, the consumer price index (CPI) inflation rate, the 3-month Treasury bill rate, 10-year Treasury yield, and a few other macroeconomic variables such as industrial production, disposable personal income, and net exports. Empirical work using the Blue Chip survey has typically focused on real GDP,

\footnotetext{
${ }^{6}$ Beginning in December 2000, the Blue Chip survey is completed by the second business day of each month.
} 
the unemployment rate, and/or CPI inflation, and we focus on these three variables in our analysis below.

Blue Chip reports the "consensus" forecast for each variable in each quarter, which is the arithmetic mean of the individual forecasts. In addition, the names and individual forecasts of each professional forecasting team are reported for each calendar year as a whole. In our regressions below, we focus on how the Blue Chip consensus forecast changed from one month to the next, and how those changes were related to FOMC monetary policy announcements. For simplicity, to reduce the number of reported coefficients in the tables below, we follow Nakamura and Steinsson (2018) and consider the change in the average of the 1-quarter-ahead, 2-quarter-ahead, and 3-quarter-ahead consensus forecasts. (These are also the horizons for which the evidence of a Fed information effect is the strongest; including the current-quarter "nowcast" or the 4-quarter-ahead forecast in the average generally weakens the statistical significance of the coefficient estimates in Table 1, below.) Although Romer and Romer (2000) is the original paper finding evidence of a Fed information effect for Blue Chip inflation forecasts, researchers using more recent samples have consistently found little or no evidence of such an effect for inflation. Thus, we focus on replicating the results in Campbell et al. (2012, henceforth CEFJ) for unemployment and Nakamura and Steinsson (2018, henceforth NS) for real GDP growth, although we consider inflation as well.

We relate these Blue Chip forecast revisions to FOMC monetary policy announcements. Over our sample, there are eight regularly-scheduled FOMC announcements per year, occurring after each scheduled FOMC meeting, spaced roughly six to eight weeks apart. In addition, the FOMC has occasionally made unscheduled monetary policy announcements that lie in between regularly-scheduled meetings, typically when the FOMC wanted to lower interest rates in response to a weakening economy and did not want to wait until the next scheduled meeting. ${ }^{7}$ We consider samples that both include and exclude these unscheduled FOMC announcements in our analysis, below.

Financial markets and professional forecasters are forward-looking, so we would not ex-

\footnotetext{
${ }^{7}$ For example, on January 22, 2008, the FOMC made an unscheduled announcement that it was cutting the federal funds rate by 75 basis points "in view of a weakening of the economic outlook and increasing downside risks to growth" (FOMC statement, Jan. 22, 2008, available on the Federal Reserve Board's website). Although the next scheduled FOMC meeting was only nine days away, Chairman Bernanke argued that "seven trading days is a long time in financial markets" and "I think we have to take a meaningful action" (FOMC transcript of January 21, 2008, available on the Federal Reserve Board's website).
} 
pect them to respond to changes in monetary policy that were widely anticipated ahead of time. For this reason, researchers typically focus on monetary policy surprises - the unexpected component of FOMC announcements. We compute monetary policy announcement surprises in two different ways, following the approaches used by CEFJ and NS. CEFJ use the "target factor" and "path factor" computed by Gürkaynak, Sack and Swanson (2005b), which correspond to the surprise change in the federal funds rate target and the surprise change in forward guidance, respectively (where forward guidance is defined to be any additional information about the future path of the federal funds rate over the next several months). These surprises are computed using changes in short-maturity federal funds futures contracts and two- to four-quarter-ahead Eurodollar futures contracts in a narrow, 30-minute window surrounding each FOMC announcement. The scale of the target factor is normalized so that it moves one-for-one with surprise changes in the target for the federal funds rate, while the scale of the path factor is normalized so that a one-unit change increases the four-quarter-ahead Eurodollar futures rate by one percentage point. ${ }^{8}$ NS use the same set of federal funds futures and Eurodollar futures contracts over the same 30-minute window, but condense the monetary policy surprise into a single dimension by taking the first principal component of those changes, which is then scaled so that a one-unit change increases the one-year zero-coupon Treasury yield (as measured by Gürkaynak, Sack and Wright, 2007) by one percentage point. Our high-frequency futures data for computing these monetary policy surprises, using either method, begins in January 1990, as discussed in Gürkaynak et al. (2005b).

\section{2 "Fed Information Effect" Regressions}

Table 1 reports results from our replication and extension of the basic information effect regressions in CEFJ and NS. The first set of columns in Table 1, labeled "Campbell et al.", considers Blue Chip forecast revision regressions of the form

$$
\text { BCrev }_{t}=\alpha+\beta \text { target }_{t}+\gamma \text { path }_{t}+\varepsilon_{t},
$$

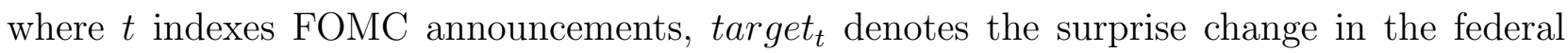
funds rate target in a 30-minute window bracketing the FOMC announcement, path $h_{t}$ de-

\footnotetext{
${ }^{8}$ For details see Gürkaynak et al. (2005b) and Campbell et al. (2012).
} 
Table 1: "Fed Information Effect" Regression Results

(1) Campbell et al.

fed funds rate fwd. guidance

Blue Chip forecast
(2) Nakamura-Steinsson

first princip. comp. "MP surprise"

(A) Replication sample: 1/1990-6/2007 for Campbell et al., 1/1995-3/2014 for NS $(N=129,120)$

$\begin{array}{lccc}\text { Unemployment rate } & -0.11 & -0.23^{*} & -0.17 \\ & (.100) & (.136) & (.292) \\ \text { Real GDP growth } & 0.10 & 0.27 & 0.92^{* *} \\ & (.181) & (.273) & (.376) \\ \text { CPI inflation } & 0.15 & 0.10 & 0.06 \\ & (.112) & (.152) & (.246)\end{array}$

(B) Full sample: 1/1990-6/2019, including unscheduled announcements $(N=217)$

$\begin{array}{lccc}\text { Unemployment rate } & -0.16 & -0.24^{*} & -0.39^{* *} \\ & (.109) & (.142) & (.188) \\ \text { Real GDP growth } & 0.16 & 0.14 & 0.33 \\ & (.171) & (.223) & (.296) \\ \text { CPI inflation } & 0.16^{*} & 0.08 & 0.29^{*} \\ & (.094) & (.123) & (.163)\end{array}$

(C) Full sample: 1/1990-6/2019, excluding unscheduled announcements $(N=206)$

$\begin{array}{lccc}\text { Unemployment rate } & 0.07 & -0.32^{* *} & -0.30 \\ & (.179) & (.151) & (.246) \\ \text { Real GDP growth } & 0.13 & 0.37^{*} & 0.54^{*} \\ & (.242) & (.203) & (.328) \\ \text { CPI inflation } & 0.12 & 0.13 & 0.27 \\ & (.150) & (.126) & (.204)\end{array}$

(D) Full sample: 1/1990-6/2019, excl. unsched. announcements and 7/2008-6/2009 $(N=198)$

$\begin{array}{lccc}\text { Unemployment rate } & -0.02 & -0.20 & -0.25 \\ & (.151) & (.129) & (.208) \\ \text { Real GDP growth } & 0.29 & 0.32^{*} & 0.64^{* *} \\ & (.209) & (.176) & (.287) \\ \text { CPI inflation } & 0.15 & 0.06 & 0.20 \\ & (.142) & (.119) & (.190)\end{array}$

Replication and extension of Campbell et al. (2012) and Nakamura and Steinsson (2018) Blue Chip forecast regression results. Campbell et al. coefficients are $\beta$ and $\gamma$ from regression BCrev $_{t}=\alpha+\beta$ target $_{t}+\gamma$ path $_{t}+\varepsilon_{t}$, where $t$ indexes FOMC announcements, target $_{t}$ denotes the surprise change in the federal funds rate in a 30 -minute window bracketing the FOMC announcement, path $_{t}$ denotes the surprise change in forward guidance in the same 30-minute window, and $\mathrm{BCrev}_{t}$ denotes the one-month change in the Blue Chip consensus forecast for the next 3 quarters, over the month bracketing the FOMC announcement. Nakamura-Steinsson coefficient is $\theta$ from regression $B$ Crev $_{t}=\phi+\theta m p s_{t}+\eta_{t}$, where $m p s_{t}$ denotes the policy surprise, calculated as the first principal component of the 30-minute changes in five short-term interest rate futures rates around the FOMC announcement. Bootstrapped standard errors in parentheses; ${ }^{* * *},{ }^{* *}$, and ${ }^{*}$ denote statistical significance at the $1 \%, 5 \%$, and $10 \%$ levels, respectively. Replication sample for Campbell et al. includes unscheduled announcements; that for Nakamura-Steinsson excludes unscheduled announcements, 7/2008-6/2009, and announcements in the first 7 days of the month. See text for details. 
notes the surprise change in forward guidance in the same 30-minute window, computed as described above, and BCrevt denotes the one-month revision in the Blue Chip consensus forecast of a given variable averaged over the 1-, 2-, and 3-quarter-ahead horizons. Note that target $_{t}$ and path $_{t}$ are high-frequency changes in the 30-minute window surrounding the FOMC announcement at date $t$, while $B C r e v_{t}$ is a lower-frequency, one-month change over the calendar month containing the FOMC announcement. The last column of Table 1, labeled "Nakamura-Steinsson", considers analogous regressions of the form

$$
B \text { Crev }_{t}=\phi+\theta \text { mps }_{t}+\eta_{t}
$$

where $m p s_{t}$ denotes the monetary policy surprise calculated as the the first principal component of the 30-minute changes in five short-term interest rate futures rates around the FOMC announcement, as described above. ${ }^{9}$ The Blue Chip survey is conducted during the first three business days of each month (first two days after Dec. 2000), and we ensure that the Blue Chip forecast revisions bracket the FOMC announcements by dropping from our analysis any FOMC announcements that occur before the beginning-of-month Blue Chip survey is completed.

In each panel of Table 1, (A) through (D), we consider the Blue Chip forecast of three different variables: the unemployment rate, real GDP growth, and the CPI inflation rate, as discussed above. In each row, coefficients reported in the "Campbell et al." column report the coefficients $\beta$ and $\gamma$ estimated using regression specification (2), while the "NakamuraSteinsson" column reports the coefficient $\theta$ estimated using regression specification (3). Standard errors are reported in parentheses below each coefficient estimate. Because the right-hand side variables in equations (2) and (3) are generated regressors, we compute these standard errors using 10,000 bootstrap replications in order to take into account the extra sampling variability associated with the computation of the target factor, path factor, and NS first principal component. ${ }^{10}$

\footnotetext{
${ }^{9}$ Note that regularly-scheduled FOMC announcements are spaced far enough apart that adjacent announcements never occur in the same month. In cases where we consider unscheduled as well as scheduled FOMC announcements, if an unscheduled announcement occurs in the same month as a scheduled announcement, then we follow Campbell et al. (2012) and add those two announcement surprises together to get one "total monetary policy announcement surprise" for that month.

${ }^{10}$ The CEFJ and NS regressors are computed using principal components that do not fit the data perfectly, hence there is some extra sampling variability associated with the factor computation itself that our
} 
In the top panel (A), we consider exactly the same sample used by CEFJ for each regression in the first set of columns, and exactly the same sample used by NS for each regression in the last column (129 and 120 observations, respectively). ${ }^{11}$ We are able to replicate the main features of their results in each case. For the CEFJ specification, we find that a surprise tightening in forward guidance is associated with a downward revision in the Blue Chip consensus unemployment forecast, by about 0.2 percentage points for every percentage point surprise in forward guidance. This relationship is borderline statistically significant, at the $10 \%$ level. As CEFJ pointed out, this response is puzzling if one thought the change in forward guidance was a pure monetary policy shock: in that case, standard macroeconomic models and VARs predict that unemployment should increase following a monetary policy tightening. NS did not report results for unemployment and instead focused on Blue Chip forecasts of real GDP. Using their specification in panel (A), we find that a surprise tightening of interest rates is associated with a significant upward revision in the Blue Chip consensus forecast for real GDP growth, by about 0.9 percentage points for each percentage point surprise in the NS monetary policy measure. Again, this estimate contradicts the pure monetary policy shock view of an FOMC announcement, according to which a monetary policy tightening should cause future GDP to decrease. Both CEFJ and NS interpret their results as evidence of a Fed information effect channel of monetary policy, as discussed in the Introduction, above.

However, even within panel (A) of Table 1, there are potential concerns with this interpretation. First, there is little or no evidence that FOMC announcements communicate any information about inflation, despite the fact that this was the original Fed information effect channel found by Romer and Romer (2000). Apparently, updating the sample to either the one used by CEFJ or NS invalidates that earlier empirical finding, an observation that

bootstrapping takes into account. Note that both CEFJ and NS treat their regressors as fixed in repeated samples, which ignores this additional source of uncertainty. However, our bootstrapped standard errors are only slightly larger than the asymptotic ones in general (cf. Table B.1) because the factor models used to compute the GSS/CEFJ/NS factors are robust and fit the data well, a result that was also found by Gürkaynak et al. (2005b).

${ }^{11}$ CEFJ use January 1990 to June 2007 as their baseline sample and include unscheduled as well as scheduled FOMC announcements. NS use January 1995 to March 2014 as their baseline sample, but exclude unscheduled FOMC announcements and all FOMC announcements from July 2008 to June 2009. In addition, NS exclude any FOMC announcement that occurred in the first seven calendar days of a given month, while CEFJ exclude announcements that occurred in the first three business days of a month, so we do that in each case in panel (A) as well, although in all other panels we exclude FOMC announcements only for the first three business days of each month (and first two days after Dec. 2000), which is sufficient to ensure that the FOMC announcement post-dates the Blue Chip survey. 
was also made by Faust et al. (2004a). Second, the CEFJ finding of an information effect for unemployment applies only to unemployment - there is no evidence in their sample that Blue Chip forecasters revise their projections for real GDP, in contrast to the findings in NS. Similarly, the NS finding of an information effect for real GDP in their sample applies only to GDP and not to unemployment, in contrast to the findings in CEFJ. This is concerning, both because it implies these results are not robust and because a true Fed information effect ought to imply that Blue Chip forecasts of both unemployment and real GDP should be affected.

In panels (B) through (D) of Table 1, we extend the CEFJ and NS analyses to the full sample for which we have data, January 1990 to June 2019. ${ }^{12}$ In panel (B), we include unscheduled as well as scheduled FOMC announcements during this period (217 observations). ${ }^{13}$ In panel (C), we exclude the eleven unscheduled FOMC announcements during this period, and in panel (D), we exclude both the unscheduled FOMC announcements and annnouncements from July 2008 to June 2009 (leaving 198 observations).

In panels (B) through (D), there is some evidence of a systematic relationship in these regressions: several of the estimated coefficients are statistically significant and in the same direction as observed by CEFJ and NS over their original samples. However, the evidence is not as consistent as a true Fed information effect ought to imply: for example, looking down the last column of Table 1, the results for real GDP are only significant when unscheduled announcements and especially July 2008 to June 2009 are excluded (panels A and D), while the results for unemployment are significant only in panel (B), when the unscheduled announcements and 2008-09 are included. If the Fed information effect is true, this would imply that in some samples there is information about real GDP but not unemployment, while in other samples there is information about unemployment but not real GDP. The CEFJ results have similar problems: in panels (A)-(B), the results for unemployment are marginally significant, but those for GDP are not, while in panel (D), the opposite is true. For inflation, there is

\footnotetext{
${ }^{12}$ The FOMC did not explicitly announce its monetary policy decisions in official press releases until February 1994; however, it still conveyed its decisions to financial markets through changes in the discount rate or through the size and type of open market operation conducted the following morning, as discussed in Gürkaynak et al. (2005b). As a robustness check, we also consider starting our sample in February 1994 and the results are similar - see Table B.2 in the Appendix.

${ }^{13}$ Consistent with the rest of the literature, we exclude the unscheduled FOMC announcement on September 17, 2001, as it occurred before the markets opened and after they had been closed for several days following the September 11 terrorist atttacks, so it's not possible to get a good high-frequency measure of the surprise component of the announcement on that date.
} 
Figure 2: Illustration of the "Fed Response to News" Channel

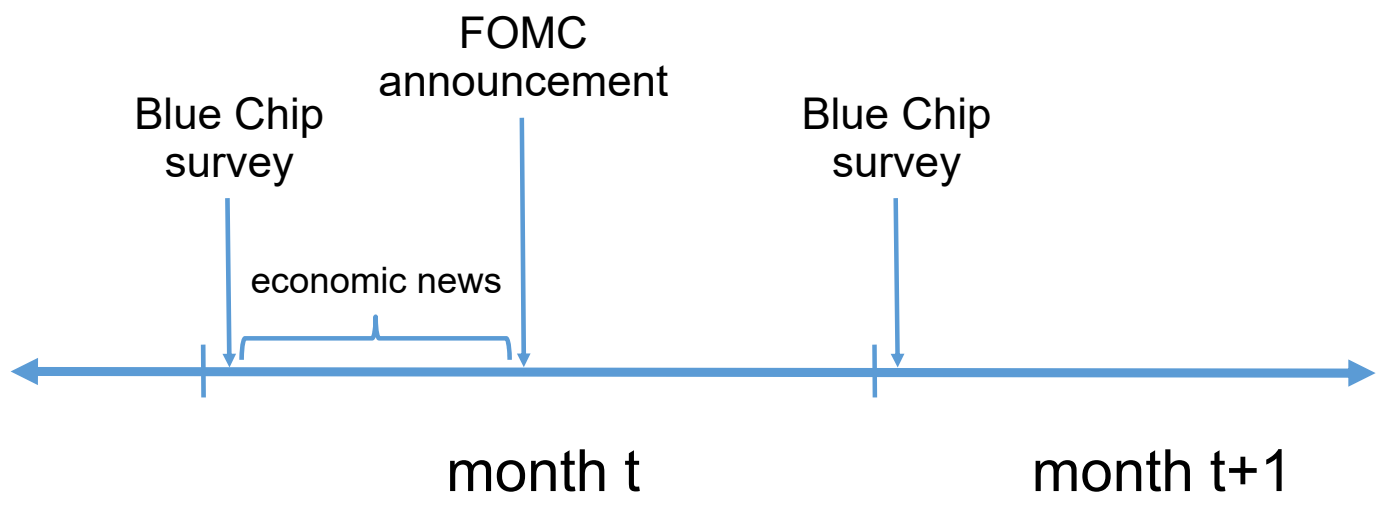

The Blue Chip survey of forecasters is conducted in the first 2-3 business days of each month, while FOMC announcements can occur at any point within the month. In between the time of the Blue Chip survey and the FOMC announcement, significant economic news, such as the employment report, is often released. See text for details.

some marginal evidence of an information effect in panel (B), but not in any of the other panels. Overall, the signs of the coefficients in the different panels are robust, but the statistical significance is sensitive to sample period and to the variable being forecast (unemployment, GDP, or inflation).

\subsection{The "Fed Response to News" Channel}

In this paper, we propose an alternative explanation of the puzzling Blue Chip survey regression results in Table 1 and Figure 1: the "Fed response to news" channel, which is illustrated in Figure 2. The Blue Chip survey of forecasters is conducted at the beginning of each month, while the FOMC announcement can occur at any point within the month. In between the beginning-of-month Blue Chip survey and the day of the FOMC announcement, significant economic news can be released. An important example is the Bureau of Labor Statistics' employment report, which is typically released on the first Friday of each month and includes detailed information about nonfarm payroll employment, the unemployment rate, average weekly hours, and average hourly earnings. Data on retail sales, international trade, industrial production, capacity utilization, and many other indicators are released around the second week of each month and, of course, new financial market data on stock prices, bond yields, and exchange rates arrives every day throughout the month. 
If the Federal Reserve and Blue Chip forecasters were both responding to the same economic news (and the Fed responded by more than financial markets expected, as argued by Cieslak (2018) and discussed in Section 3, below), that could explain all of the results in Table 1 and Figure 1. Positive economic news, for example, would lead to additional tightening by the Fed and would also cause professional forecasters to revise their GDP and inflation forecasts upward, and their unemployment forecasts downward. Thus, we would estimate positive coefficients for GDP growth and inflation and negative coefficients for unemployment in the Blue Chip survey regressions, even in the absence of a Fed information effect.

In fact, the Fed response to news channel can explain the results in Table 1 more consistently than the Fed information effect. First, the observation that in some samples the coefficients are significant only for real GDP, while in others the coefficients are significant only for unemployment, is consistent with the Fed and Blue Chip both responding to incoming news about GDP in the first case and unemployment in the second. In contrast, the Fed information effect offers no explanation why there would be different information in FOMC announcements in different subsamples. Second, the significant coefficients for Blue Chip inflation forecasts in panel (B) of Table 1 can be explained by both the Fed and Blue Chip receiving significant news about inflation during in this sample; in contrast, the Fed information effect has difficulty explaining why FOMC announcements would contain information about inflation in this period and not others. Third, the Fed response to news channel is consistent with the finding in Figure 1 that all the influential observations in the upper-right corner of the figure occurred when the economy was in an expansion, while all the influential observations in the lower-left corner occurred when the economy was clearly weakening: according to this channel, both the Fed and Blue Chip forecasters were responding to incoming news about the economy. In contrast, the Fed information effect does not explain why negative information about the economy is only revealed by FOMC announcements in recessions, while positive information about the economy is only revealed in expansions.

\section{Evidence Economic News Is an Omitted Variable}

According to the Fed response to news channel illustrated in Figure 2, publicly available economic news released before an FOMC announcement is an omitted variable in regressions (2) 
and (3). ${ }^{14}$ If the pre-FOMC economic news (i) affects Blue Chip forecast revisions and (ii) is correlated with the right-hand side variables in regressions (2)-(3), then the estimated coefficients in those regressions will be biased. Although one might hope that the high-frequency monetary policy surprises in (2)-(3) control for the effects of all publicly available information prior to each FOMC announcement, the scatter plot in Figure 1 raises serious concerns that there is still significant correlation remaining: the largest monetary policy tightening surprises all occurred during periods of economic expansion, while the largest monetary policy easing surprises happened during economic downturns.

In this section, we document three important empirical findings: First, economic news released during the month is extremely informative about Blue Chip forecast revisions that month (which is not surprising). Second, economic news released prior to the FOMC announcement is correlated with the high-frequency monetary policy surprises in regressions (2)(3), suggesting that there is an omitted variables bias in those regressions. Third, including pre-FOMC economic news as an additional explanatory variable in regressions (2)-(3) drives out the empirical evidence of a Fed information effect. Taken together, this evidence strongly supports the Fed response to news channel.

\subsection{Economic News Predicts Blue Chip Forecast Revisions}

We first show that economic news is a strong predictor of Blue Chip forecast revisions. This is not surprising: economic data is released every month, and the professional forecasters in the Blue Chip survey typically revise their forecasts for GDP, unemployment, and inflation in response to those data.

We focus on three different measures of economic news spanning a variety of announcement types. First, we consider the nonfarm payrolls release from the employment report, which is typically announced on the first Friday of each month. This has the advantage of being a very simple yet informative measure of economic news for the month, since the nonfarm payrolls release is widely regarded by financial market participants as the most informative of

\footnotetext{
${ }^{14}$ We focus on economic news released before the FOMC announcement because that news is clearly publicly available before the FOMC announcement itself, and thus cannot represent a Fed information effect about future data releases. However, in principle any economic news released after the FOMC announcement is an omitted variable in regressions (2)-(3) as well.
} 
all the macroeconomic data releases (e.g., Andersen and Bollerslev, 1998). ${ }^{15}$ Second, we consider a more comprehensive measure of economic news, the "big data" business cycle indicator of Brave, Butters and Kelley (2019, henceforth BBK). This index incorporates the information from all of the standard macroeconomic data releases each month to come up with a single measure of economic activity, with higher numbers indicating a stronger economy. It is thus much broader than nonfarm payrolls alone, but has the disadvantage of including data that are released after the FOMC announcement as well as before. ${ }^{16}$ Third, we use the percent change in the S\&P 500 index from one quarter (thirteen weeks) prior to the FOMC announcement to the day before the FOMC announcement. Although the S\&P 500 is noisy, it provides a summary of the market's interpretation of all of the economic news released over that period; we consider the 13-week change because it's a more powerful predictor of the Blue Chip forecast revision than the change from the beginning of the month, which covers only a few days and can be very volatile.

We measure the effects of these news measures on Blue Chip forecast revisions using regressions of the form

$$
\text { BCrev }_{t}=\alpha+\beta \text { news }_{t}+\varepsilon_{t},
$$

where $t$ indexes months containing an FOMC announcement, as in Section 2, and $B C r e v_{t}$ denotes the revision in the Blue Chip consensus forecast of a given variable over month $t$. While one can also perform regression (4) on a sample including all months, we focus on revisions around FOMC announcements in order to investigate the potential omitted variables problem in regressions (2)-(3).

The results of these regressions are reported in Table 2. The table is divided into four panels that cover the same samples as in Table 1. The first column reports results using

\footnotetext{
${ }^{15}$ We have data on the employment report release date and the nonfarm payrolls release itself from Haver Analytics/Money Market Services. If the employment report is released in the first two business days of the month (three days prior to Dec. 2000), then we treat the news for that observation as zero since it may not post-date the Blue Chip forecast, although this has little effect on our estimates below. Similarly, if the FOMC announcement occurs before the employment report that month, we treat the news for that observation as zero, although this again has very little effect on our estimates. The nonfarm payrolls release reports the change in nonfarm payroll employees from the previous month, in thousands of workers; we divide this number by 1000 to make the scaling of the coefficients in Table 2 comparable to the other two news measures. Note that the employment data refers to month $t-1$, because it is data for month $t-1$ that is released in month $t$.

${ }^{16}$ Note that the BBK index for month $t-1$ is computed using data released in month $t$ and is reported by the Chicago Fed at the beginning of month $t+1$. In regression (4), we use the BBK index for month $t-1$ as our measure of $n e w s_{t}$, since it is computed using the economic data that was released in month $t$.
} 
Table 2: Economic News Predicts Blue Chip Forecast Revisions

Economic news measure:

$\begin{array}{llll}\text { Blue Chip Forecast } & \text { (1) Nonfarm payrolls } & \text { (2) BBK index } & \text { (3) } \Delta \operatorname{logS} \& \text { P500 }\end{array}$

(A1) Campbell et al. replication sample: 1/1990-6/2007 $(N=129)$

$\begin{array}{lccc}\text { Unemployment rate } & -.211^{* * *} & -.060^{* * *} & -0.37^{* * *} \\ & (.047) & (.009) & (.116) \\ \text { Real GDP growth } & .016 & .047^{* *} & 0.95^{* * *} \\ & (.093) & (.019) & (.193)\end{array}$

(A2) NS replication sample: 1/1995-3/2014, excluding 7/2008-6/2009 $(N=120)$
Unemployment rate
$-.162^{* * *}$
$-.061^{* * *}$
$-0.60^{* * *}$
$(.062)$
$(.016)$
$(.133)$
Real GDP growth
.028
$.092^{* * *}$
$1.01^{* * *}$
$(.084)$
$(.020)$

(B) Full sample: 1/1990-6/2019, including unscheduled announcements $(N=217)$

$\begin{array}{llll}\text { Unemployment rate } & -.298^{* * *} & -.078^{* * *} & -0.69^{* * *} \\ & (.042) & (.007) & (.102) \\ \text { Real GDP growth } & .127^{*} & .069^{* * *} & 1.09^{* * *} \\ & (.071) & (.013) & (.150)\end{array}$

(C) Full sample: 1/1990-6/2019, excluding unscheduled announcements $(N=206)$

$\begin{array}{llll}\text { Unemployment rate } & -.292^{* * *} & -.081^{* * *} & -0.74^{* * *} \\ & (.043) & (.007) & (.106) \\ \text { Real GDP growth } & .128^{* *} & .071^{* * *} & 1.14^{* * *} \\ & (.064) & (.011) & (.135)\end{array}$

(D) Full sample: 1/1990-6/2019, excl. unsched. announcements and 7/2008-6/2009 $(N=198)$

$\begin{array}{lccc}\text { Unemployment rate } & -.182^{* * *} & -.067^{* * *} & -0.54^{* * *} \\ & (.046) & (.010) & (.109) \\ \text { Real GDP growth } & .051 & .065^{* * *} & 1.05^{* * *} \\ & (.065) & (.015) & (.135)\end{array}$

Estimated coefficients $\beta$ from regressions $B C r e v_{t}=\alpha+\beta$ new $s_{t}+\varepsilon_{t}$, where $t$ indexes months of FOMC

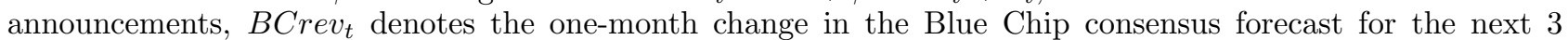
quarters for the variable listed in each row, and news denotes the measure of economic news listed in each column. BBK index is from Brave et al. (2019). Bootstrapped standard errors in parentheses; ***, **, and * denote statistical significance at the 1\%,5\%, and $10 \%$ levels, respectively. Replication sample for Campbell et al. (2012) includes unscheduled announcements; that for Nakamura and Steinsson (2018) excludes unscheduled announcements and 7/2008-6/2009. See text for details. 
nonfarm payrolls as the measure of economic news, the second column uses the BBK index as the news measure, and the third column uses the percent change in the S\&P 500. ${ }^{17}$ Within each sample, we perform regression (4) on the Blue Chip forecast revision for the unemployment rate and for real GDP growth. We do not report results for Blue Chip inflation forecasts in the interest of space and because there was no evidence of a Fed information effect for inflation in Table 1; moreover, the three economic news measures in Table 2 primarily measure news about economic activity rather than inflation, so they have little predictive power for Blue Chip inflation forecast revisions.

Not surprisingly, economic news is a very strong predictor of Blue Chip forecast revisions. The coefficients in Table 2 have the expected sign in every case and are almost all highly statistically significant. There is no question that these economic news measures are associated with subsequent Blue Chip forecast revisions.

\subsection{Economic News Predicts Monetary Policy Surprises}

We next show that the three economic news measures above are correlated with the highfrequency monetary policy surprises in regressions (2)-(3), using regressions of the form

$$
m p s_{t}=\alpha+\beta \text { news } t+\varepsilon_{t}
$$

where $t$ indexes FOMC announcements, $m p s_{t}$ is a high-frequency measure of the monetary policy surprise in a narrow window of time around the FOMC announcement (either the "target" factor, the "path" factor, or the Nakamura-Steinsson first principal component), and news $s_{t}$ denotes one of the three measures of economic news described above.

The results from this regression are reported in Table 3. There are four panels in the table, corresponding to the same samples as in Tables 1 and 2. Each row considers a single high-frequency measure of the monetary policy surprise, either the "target factor" from Campbell et al. (2012) and Gürkaynak et al. (2005b), the "path factor" from those papers, or the monetary policy surprise measure from Nakamura and Steinsson (2018). Each column considers one of the three economic news measures described above, and each element of the

\footnotetext{
${ }^{17}$ Thus, each coefficient in Table 2 corresponds to its own regression. One can also include all three measures of news in regression (4) simultaneously, but for simplicity we just report the univariate regression results in the table.
} 
Table 3: Economic News Predicts High-Frequency Monetary Policy Surprises

Monetary policy

Economic news measure:

surprise measure

(1) Nonfarm payrolls

(2) BBK index

(3) $\Delta \log \mathrm{S} \& \mathrm{P} 500$

(A) Replication sample: 1/1990-6/2007 for Campbell et al., 1/1995-3/2014 for NS $(N=129,120)$
fed funds target factor
$.158^{* * *}$
$.033^{* * *}$
(.011)
.179
.032
(.038)
$.017^{* *}$
(.0085)
fwd guidance path factor
$.041^{*}$
$.013^{* *}$
$.235^{* * *}$
NS MP surprise
(.022)
(.0059)
(.088)
$.096^{*}$
(.051)

(B) Full sample: 1/1990-6/2019, including unscheduled announcements $(N=217)$

$\begin{array}{lccc}\text { fed funds target factor } & .095^{* * *} & .017^{* *} & .217^{* * *} \\ \text { fwd guidance path factor } & (.035) & (.0067) & (.084) \\ & .024 & .013^{* * *} & .187^{* * *} \\ \text { NS MP surprise } & (.024) & (.0046) & (.058) \\ & .058^{* * *} & .014^{* * *} & .188^{* * *} \\ & (.020) & (.0039) & (.048)\end{array}$

(C) Full sample: 1/1990-6/2019, excluding unscheduled announcements $(N=206)$

$\begin{array}{lccc}\text { fed funds target factor } & .045^{* *} & .007^{*} & .065 \\ \text { fwd guidance path factor } & (.020) & (.0039) & (.051) \\ & .027 & .017^{* * *} & .254^{* * *} \\ \text { NS MP surprise } & (.024) & (.0045) & (.057) \\ & .035^{* *} & .011^{* * *} & .148^{* * *} \\ & (.015) & (.0029) & (.037)\end{array}$

(D) Full sample: 1/1990-6/2019, excl. unsched. announcements and 7/2008-6/2009 $(N=198)$
fed funds target factor
$.048^{* *}$
$.012^{* *}$
.018
$(.024)$
(.0058)
(.059)
fwd guidance path factor
.008
(.028)
$.023^{* * *}$
$.187^{* * *}$
.028
(.018)
(.0067)
(.068)
NS MP surprise
$.017^{* * *}$
$.098^{* *}$
(.0044)
(.044)

Estimated coefficients $\beta$ from regressions $m p s_{t}=\alpha+\beta$ news $s_{t}+\varepsilon_{t}$, where $t$ indexes FOMC announcements, $m p s_{t}$ denotes the 30-minute window measure of the monetary policy surprise listed in each row, and news denotes the measure of economic news listed at the top of each column. BBK index is from Brave et al. (2019). Bootstrapped standard errors in parentheses; ${ }^{* * *},{ }^{* *}$, and ${ }^{*}$ denote statistical significance at the 1\%, 5\%, and 10\% levels, respectively. Replication sample for Campbell et al. (2012) includes unscheduled announcements; that for Nakamura and Steinsson (2018) excludes unscheduled announcements and 7/2008-6/2009. See text for details. 
table reports the coefficient estimate $\beta$ from regression (5). ${ }^{18}$

It is clear from Table 3 that there is significant predictability in these high-frequency monetary policy surprises. The predictability is robust across samples and across different measures of economic news, and is often highly statistically significant. Moreover, the signs of the coefficients are positive in every case, consistent with the Fed response to news channel (and Figure 1): when the economic news is positive, the FOMC is more likely to surprise markets with a subsequent tightening, and when the economic news is negative, the FOMC is more likely to surprise markets with a subsequent easing.

This predictability is perhaps surprising. Under the standard assumption of Full Information Rational Expectations (FIRE) in financial markets, interest rates and interest rate futures should incorporate all publicly available information up to the time they are traded. Thus, the high-frequency monetary policy surprises (i.e., interest rate changes) on the lefthand side of regression (5) should be unpredictable based on all publicly available information that predates the surprise. Instead, the economic news in Table 3 is significantly correlated with the upcoming monetary policy surprises. Previous studies by Miranda-Agrippino (2017), Cieslak (2018), and Karnaukh (2019) also find similar predictability results, although they do not consider the omitted variables problem that we are studying in this section.

There are two possible explanations for the predictability in Table 3: either (i) financial market participants violated the FIRE assumption, or (ii) those market participants satisfied FIRE, but required a risk premium to compensate them for interest rate risk around FOMC announcements. Miranda-Agrippino (2017) argues in favor of the second explanation, that the predictability in Table 3 represents a risk premium. However, Piazzesi and Swanson (2008) estimate that this risk premium is small and Cieslak (2018) argues that the risk premium would have to be implausibly large to explain the estimated degree of predictability in the table and that a risk premium interpretation is inconsistent with a variety of other financial market evidence.

Instead, Cieslak (2018) presents evidence that financial markets did not have full information about the Fed's monetary policy reaction function - thus violating the FIRE assumptionand in particular, underestimated ex ante how responsive the Fed would be to the economy.

\footnotetext{
${ }^{18}$ Thus, each coefficient in Table 3 corresponds to its own regression. One can also include all three measures of news in regression (5) simultaneously, but for simplicity we include each news measure by itself in Table 3 .
} 
This would lead to ex post predictability of monetary policy surprises of the type seen in Table 3, even if those surprises were unpredictable ex ante (see Section 7, below, for a simple model). We do not take a stand on why market participants might have underestimated the Fed's responsiveness to news, but one possibility is that the Fed has gradually become more responsive to news about output over time - that is, the Fed under Volcker was less responsive to news about output than the Fed under Greenspan, which was less responsive than the Fed under Bernanke, etc. (see Section 7 for additional discussion). Regardless of the reason, the crucial point for our analysis is that the high-frequency monetary policy surprises in the Fed information effect regressions (2)-(3) are correlated with the omitted economic news variables, which leads to an omitted variables bias in those regressions.

\subsection{Economic News Drives Out the "Fed Information Effect"}

The results in Tables 2-3 imply that economic news is an omitted variable in regressions (2)(3) and that this omitted variable is correlated with the monetary policy surprises in those regressions. As a result, the coefficients in regressions (2)-(3) will be biased.

To correct for this bias, we re-estimate regressions (2)-(3) with explicit controls for economic news:

$$
\text { BCrev }_{t}=\alpha+\beta \text { target }_{t}+\gamma \text { path }_{t}+\delta \text { news }_{t}+\varepsilon_{t}
$$

and

$$
B C r e v_{t}=\phi+\theta m p s_{t}+\psi n e w s_{t}+\eta_{t}
$$

where $t$ indexes months with FOMC announcements, and the variables in (6)-(7) are as defined previously, although here we let news $s_{t}$ be a vector that contains all three measures of economic news simultaneously. ${ }^{19}$

The results are reported in Table 4, which has essentially the same structure as Table 1. The table is divided into four panels covering the same samples as in Tables 1-3. In each row, the "Campbell et al." column reports the coefficients $\beta$ and $\gamma$ from regression (6), while the "Nakamura-Steinsson" column reports the coefficient $\theta$ from (7). Each row corresponds to the

\footnotetext{
${ }^{19}$ Because the information in the BBK index is not completely known by the time of the FOMC announcement, we also consider a version of Table 4 that excludes that index from the news $s_{t}$ variable, and the results are very similar. See Appendix Table B.3.
} 
Table 4: Economic News Drives Out the "Fed Information Effect"

\begin{tabular}{|c|c|c|c|}
\hline & (1) Camp & bell et al. & (2) Nakamura-Steinsson \\
\hline Blue Chip forecast & $\begin{array}{l}\text { fed funds rate } \\
\text { target factor }\end{array}$ & $\begin{array}{l}\text { fwd. guidance } \\
\text { path factor }\end{array}$ & $\begin{array}{l}\text { first princip. comp. } \\
\text { MP surprise }\end{array}$ \\
\hline
\end{tabular}

(A) Replication sample: 1/1990-6/2007 for Campbell et al., 1/1995-3/2014 for NS $(N=129,120)$

$\begin{array}{lccc}\text { Unemployment rate } & .088 & -.036 & .191 \\ & (.093) & (.127) & (.266) \\ \text { Real GDP growth } & -.045 & -.083 & .502 \\ & (.181) & (.267) & (.307)\end{array}$

(B) Full sample: 1/1990-6/2019, including unscheduled announcements $(N=217)$

$\begin{array}{lccc}\text { Unemployment rate } & .104 & .091 & .210 \\ & (.089) & (.116) & (.157) \\ \text { Real GDP growth } & -.110 & -.328^{*} & -.375 \\ & (.148) & (.195) & (.261)\end{array}$

(C) Full sample: 1/1990-6/2019, excluding unscheduled announcements $(N=206)$

$\begin{array}{lccc}\text { Unemployment rate } & .335^{* *} & .157 & .502^{* *} \\ & (.137) & (.124) & (.195) \\ \text { Real GDP growth } & -.082 & -.280 & -.385 \\ & (.193) & (.176) & (.278)\end{array}$

(D) Full sample: 1/1990-6/2019, excl. unsched. announcements and 7/2008-6/2009 $(N=198)$

$\begin{array}{lccc}\text { Unemployment rate } & .129 & .054 & .179 \\ & (.132) & (.117) & (.183) \\ \text { Real GDP growth } & .204 & -.059 & .119 \\ & (.175) & (.153) & (.245)\end{array}$

Coefficients in Campbell et al. columns are $\beta$ and $\gamma$ from regressions $B C r e v_{t}=\alpha+\beta$ target $_{t}+\gamma$ path $_{t}+$ $\delta$ news $_{t}+\varepsilon_{t}$, where $t$ indexes FOMC announcements, target $_{t}$, path $_{t}$, and $B$ Crev $_{t}$ are as defined in Table 1 , and news $s_{t}$ is a vector that contains the three measures of economic news described above. Coefficients in Nakamura-Steinsson column are $\theta$ from regressions $B$ Crev $_{t}=\phi+\theta m p s_{t}+\psi$ news $s_{t}+\eta_{t}$, where $m p s_{t}$ is as defined in Table 1. Bootstrapped standard errors in parentheses; ${ }^{* * *},{ }^{* *}$, and ${ }^{*}$ denote statistical significance at the $1 \%, 5 \%$, and $10 \%$ levels, respectively. See notes to Table 1 and text for details.

Blue Chip forecast revision for a different variable (the unemployment rate or real GDP), and as in Table 2 we exclude the Blue Chip inflation forecasts.

The results in Table 4 are strikingly different from Table 1. First, the vast majority of coefficients in Table 4 have the conventional (i.e., non-information-effect) sign - positive for the unemployment rate and negative for real GDP. Thus, controlling for economic news, the effect of Federal Reserve monetary policy announcements on Blue Chip forecast revisions looks very standard. These coefficients are generally not statistically significant, but that should 
not be too surprising, given that the high-frequency monetary policy surprises are typically small (standard deviation of a few basis points) and are only a small part of the information about the economy released during each month. Three coefficients in the table are statistically significant at the 10 percent level or better in the standard (non-information-effect) direction, while no coefficient is significant in the information effect direction.

We conclude that economic news is an omitted variable in the standard Fed information effect regressions (2)-(3), that economic news is correlated with the right-hand-side variables in those regressions, and that the resulting omitted variables bias is substantial. Once we control for this omitted variable, as in regressions (6)-(7), the sign of the coefficients on the monetary policy announcement surprises reverses sign and looks conventional.

\section{High-Frequency Stock Market Evidence}

We next provide high-frequency evidence from the stock market that also suggests that the Fed information effect is small or nonexistent. Standard economic theory predicts that a pure monetary policy tightening should cause stock prices to fall, as discussed, for example, by Bernanke and Kuttner (2005). First, higher interst rates imply that future corporate profits should be discounted more heavily, implying a lower present value, and second, higher interest rates imply that future GDP and future corporate profits should be lower on average, reducing the present value of those profits further.

If higher interest rates have a significant Fed information component, however, then the effect on the stock market is ambiguous. Higher interest rates imply that future corporate profits should be discounted more heavily, as above, but now the higher interest rates signal that GDP and corporate profits will be higher in the future, rather than lower. The net effect of these two forces on the stock market is ambiguous.

Recent papers on the Fed information effect, however, have argued that the net effect is typically positive - that is, higher interest rates cause stock prices to rise when a strong information effect is present (Jarocinski and Karadi, 2020; Cieslak and Schrimpf, 2019; Lunsford, 2019). In fact, Jarocinski and Karadi (2020) and Cieslak and Schrimpf (2019) identify information shocks (as opposed to pure monetary policy shocks) based on how the stock market responds to higher interest rates, with a positive stock market response indicating an infor- 
mation shock and a negative stock market response a pure monetary policy shock. In this section, we likewise use the high-frequency stock market respone to FOMC announcements to help discern whether a significant information effect is present.

\subsection{Stock Market Responses to FOMC Announcements}

We first estimate the typical response of stock prices to FOMC monetary policy announcements. We run regressions analogous to (2)-(3), but now with the dependent variable being the percent change in the $\mathrm{S} \& \mathrm{P} 500$ stock price index in a 30-minute window surrounding each FOMC announcement:

$$
\Delta \log \mathrm{S} \& \mathrm{P} 500_{t}=\alpha+\beta \text { target }_{t}+\gamma \text { path }_{t}+\varepsilon_{t}
$$

and

$$
\Delta \log \mathrm{S} \& \mathrm{P} 500_{t}=\phi+\theta m p s_{t}+\eta_{t}
$$

The results are reported in Table 5. The first set of columns in each row reports the estimated coefficients $\beta$ and $\gamma$ and the $R^{2}$ from regression (8), while the last two columns report the coefficient $\theta$ and the $R^{2}$ from regression (9). As in previous tables, bootstrapped standard errors from 10,000 bootstrap replications are reported in parentheses beneath each coefficient, to account for the generated regressors in (8)-(9). The four panels (A) through (D) report results for each of the four samples considered in Table $1 .^{20}$

The results are very much in line with Bernanke and Kuttner (2005), although the measures of monetary policy surprises in Table 5 are somewhat different. A one percentage point surprise increase in the federal funds rate target (in the first column) causes stock prices to fall about 3-4 percent, consistent with the estimates in Bernanke and Kuttner (2005), Gürkaynak et al. (2005b), and others. ${ }^{21}$ A surprise increase in forward guidance (that raises the oneyear-ahead expected federal funds rate by one percentage point) causes stock prices to fall about 2-3 percent, consistent with Gürkaynak et al. (2005b), D'Amico and Farka (2011), and

\footnotetext{
${ }^{20}$ The number of observations in each panel of Table 5 is somewhat larger than in Table 1 because we do not need to drop announcements that occur in the first 2-3 business days of each month (or 7 days for the NS replication sample), as we did for the Blue Chip survey regressions. The results are very similar if we do drop those observations.

${ }^{21}$ See also D'Amico and Farka (2011) and Swanson (2019).
} 
Table 5: High-Frequency Stock Market Response to FOMC Announcements

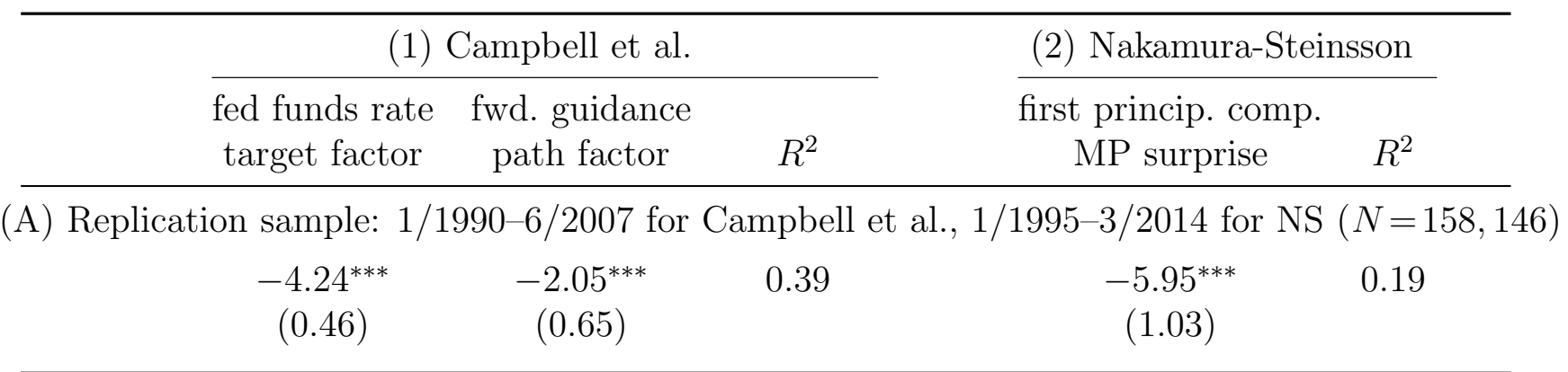

(B) Full sample: 1/1990-6/2019, including unscheduled announcements $(N=259)$

$\begin{array}{cccc}-4.37^{* * *} & -2.52^{* * *} & 0.32 & -7.82^{* * *} \\ (0.45) & (0.54) & & (0.72)\end{array}$

(C) Full sample: 1/1990-6/2019, excluding unscheduled announcements $(N=236)$

\begin{tabular}{|c|c|c|c|}
\hline $\begin{array}{c}-3.11^{* * *} \\
(0.64)\end{array}$ & $\begin{array}{c}-3.14^{* * *} \\
(0.51)\end{array}$ & 0.21 & $\begin{array}{c}-6.53^{* * *} \\
(0.82)\end{array}$ \\
\hline
\end{tabular}

(D) Full sample: 1/1990-6/2019, excl. unscheduled announcements and 7/2008-6/2009 $(N=228)$
$-2.81^{* * *}$
$-3.02^{* * *}$
0.21
$-6.03^{* * *}$
0.21
$(0.64)$
$(0.51)$
$(0.78)$

Regression results for stock market response to FOMC announcements. Campbell et al. coefficients are $\beta$ and $\gamma$ from regression $\Delta \log \mathrm{S} \& \mathrm{P} 500_{t}=\alpha+\beta$ target $_{t}+\gamma$ path $_{t}+\varepsilon_{t}$, where $t$ indexes FOMC announcements, target $_{t}$ and path $_{t}$ denote the surprise change in the federal funds rate and forward guidance in a 30-minute window bracketing the FOMC announcement, and $\Delta \log \mathrm{S} \& \mathrm{P} 500_{t}$ denotes the percent change in the S\&P 500 over the same 30-minute window. Nakamura-Steinsson coefficient is $\theta$ from regression $\Delta \log \mathrm{S} \& \mathrm{P} 500_{t}=\phi+\theta m p s_{t}+\eta_{t}$, where $\mathrm{mps}_{t}$ denotes the NS monetary policy surprise measure in a 30-minute window bracketing the FOMC announcement. Bootstrapped standard errors in parentheses; ${ }^{* * *}$ denotes statistical significance at the $1 \%$ level. See notes to Table 1 and text for details.

Swanson (2019). ${ }^{22}$ An increase in the NS monetary policy surprise that raises the one-year Treasury yield by one percentage point has an even larger, 6-8 percent negative effect on stock prices, roughly equal to the combined target and path factor effects from the first set of columns. All of the estimated coefficients in Table 5 are highly statistically significant over all of the sample periods considered.

The high statistical significance in Table 5 and the robustness of the coefficients across samples contrast sharply with the Blue Chip survey regressions in Table 1 . In Table 5, there is no question that the U.S. stock market responds negatively, on average, to a monetary policy

\footnotetext{
${ }^{22}$ Note that the estimates in Gürkaynak et al. (2005b) for the path factor were negative but statistically insignificant, while our extended sample produces a strongly significant coefficient, in line with D'Amico and Farka (2011) and Swanson (2019).
} 
Table 6: Ten Most Influential Observations in Nakamura-Steinsson GDP Forecast Regression

\begin{tabular}{cccccc}
\hline Date & $\begin{array}{c}\text { Effect on } \\
t \text {-statistic }\end{array}$ & $\begin{array}{c}\text { MP surprise } \\
\text { mps }_{t}\end{array}$ & $\begin{array}{c}\text { BCrev }_{t}, \\
\text { GDP }\end{array}$ & $\begin{array}{c}\Delta \log \\
\mathrm{S}^{\prime} P 500_{t}\end{array}$ & $\begin{array}{c}\text { bus. cycle } \\
\text { indicator }\end{array}$ \\
\hline $9 / 2007$ & 0.554 & -0.138 & -0.2 & 1.33 & -0.29 \\
$1 / 2008$ & 0.351 & -0.076 & -0.3 & 0.76 & -0.81 \\
$6 / 2003$ & 0.312 & 0.099 & 0.133 & -0.27 & -0.38 \\
$3 / 2001$ & 0.291 & -0.059 & -0.3 & -0.68 & -1.45 \\
$4 / 2008$ & 0.278 & -0.055 & -0.3 & 0.31 & -1.52 \\
$11 / 1999$ & 0.240 & 0.068 & 0.167 & -0.42 & 0.86 \\
$1 / 2004$ & 0.224 & 0.088 & 0.1 & -0.97 & 0.38 \\
$5 / 1999$ & 0.224 & 0.073 & 0.133 & -1.44 & 0.19 \\
$12 / 1995$ & 0.207 & -0.036 & -0.3 & 0.26 & -0.08 \\
$3 / 1997$ & 0.155 & 0.051 & 0.133 & -0.67 & 0.80 \\
\hline
\end{tabular}

Ten most influential observations in Nakamura-Steinsson regression (3), as measured by the change in the $t$-statistic due to inclusion vs. exclusion of the observation. Also shown is the NS measure of the monetary policy surprise $m p s_{t}$, the change in the Blue Chip consensus forecast of real GDP $\left(B C r e v_{t}\right)$, the 30-minutewindow response of the S\&P 500 to the FOMC announcement, and the monthly business cycle indicator from Brave et al. (2019). See text for details.

tightening surprise. By itself, this result is not surprising - it corresponds to the conventional wisdom described in Bernanke and Kuttner (2005) and others. But compared to Table 1, it poses a challenge for the Fed information effect story: if the Fed information effect is true, and information shocks have a positive effect on stock prices, as described by Jarocinski and Karadi (2020) and Cieslak and Schrimpf (2019), then why are the results in Table 5 so strongly and consistently negative? Those results suggest that, if there is a Fed information effect, then it must not be very large on average.

\subsection{Market Responses to Influential FOMC Announcements}

Perhaps the Fed information effect is small on average, but is very important on a few special dates. To investigate this possibility, Table 6 reports the ten most influential observations in the Nakamura and Steinsson (2018) GDP regression from Table 1 and Figure 1, over their original sample. These are the ten observations that provide by far the most evidence for a Fed information effect in their regressions and in Figure 1.

The ten observations in Table 6 are ordered by their contribution to the $t$-statistic in regression (3), reported in the second column. ${ }^{23}$ The first column of the table reports the

\footnotetext{
${ }^{23}$ This "Effect on $t$-statistic" is computed as the difference between the $t$-statistic for the coefficient $\theta$ in
} 
Table 7: Stock Market Response to Ten Most "Information-Laden" FOMC Announcements

\begin{tabular}{cc}
\hline \multicolumn{2}{c}{ first princip. comp. } \\
MP surprise & $R^{2}$ \\
\hline (A) Ten most information-laden observations in NS sample, from Table $6 \quad(N=10)$ \\
$-8.04^{* * *}$ & 0.64 \\
$(2.13)$ & \\
\hline (B) NS sample, excluding the ten observations from Table $6 \quad(N=136)$ \\
$-4.96^{* * *}$ \\
$(1.24)$
\end{tabular}

Coefficient $\theta$ from regressions $\Delta \log \mathrm{S} \& \mathrm{P} 500_{t}=\phi+\theta m p s_{t}+\eta_{t}$, where $t$ indexes the FOMC announcements described in each panel, $\mathrm{mps}_{t}$ denotes the NS monetary policy surprise in a 30-minute window bracketing the FOMC announcement, and $\Delta \log \mathrm{S} \& \mathrm{P} 500_{t}$ denotes the percent change in the S\&P 500 over the same 30 -minute window. Standard errors in parentheses; ${ }^{* * *}$ denotes statistical significance at the $1 \%$ level. See notes to Table 5 and text for details.

month and year of each observation (the first eight of these are also labeled in Figure 1). The Nakamura-Steinsson (NS) measure of the monetary policy surprise for each announcement is reported in the third column, followed by the change in the Blue Chip forecast for GDP that month, the percent change in the S\&P 500 stock price index in the 30-minute window bracketing the announcement, and the BBK index for that month in the last column. For simplicity, we focus on the Blue Chip GDP forecast revisions in Table 6, but for every observation in the table, the inflation forecast revision has the same sign as the GDP revision, and the unemployment forecast revision has the opposite sign.

By construction, the ten observations in Table 6 display a positive relationship between the NS monetary policy surprises and Blue Chip GDP forecast revisions, because these are the ten observations that are the most important for the Fed information effect result in Figure 1 and panel (A) of Table 1. But even for these ten supposedly very information-laden FOMC announcements, the relationship between the monetary policy surprise and the stock market response is strongly negative in nine out of the ten cases.

Table 7 reports the results from applying regression (9) to these ten information-laden observations and compares them to the results for the rest of the NS sample excluding those ten observations. If a Fed information effect were present, then the stock market should respond positively — or, at least, less negatively - to these ten announcements compared to the regression (3) including vs. excluding that one observation from the sample. 
rest of the NS sample. In fact, the opposite is true: the stock market responded even more negatively on these ten dates than it did for the NS sample as a whole.

In contrast to the Fed information effect, the Fed response to news channel is consistent with all of the evidence in Tables 5-7. The last column of Table 6 reports the BBK index as a summary of the state of the business cycle. Note that all five observations in Table 6 with negative policy surprises and downward GDP forecast revisions occurred when the economy was weak. In all five of these cases, the FOMC cut the federal funds rate in response to the weak economy, but the market was partly surprised by these decisions, as measured by the monetary policy surprise. In response to the monetary policy easings, the stock market rallied strongly in four out of the five cases, consistent with standard predictions of the effects of monetary policy on stocks (e.g., Bernanke and Kuttner, 2005). For the five positive monetary policy surprises in Table 6 , the same observations hold, but in the opposite direction. ${ }^{24}$

\section{High-Frequency Private Sector Forecast Evidence}

One of the main advantages of financial market data, such as stock prices, is that it is available at high frequency, which allows us to focus on how a given asset price responds to a single important event in isolation, such as an FOMC announcement. By contrast, the Blue Chip survey of forecasters is conducted only once per month, so it's impossible to isolate the effects of an FOMC announcement on Blue Chip forecasts using those data.

In this section, we present new data from private sector forecasters that does allow us to isolate the effects of FOMC announcements on their forecasts. First, we obtained daily "GDP tracking" forecasts of real GDP from Macroeconomic Advisers, a multiple-award-winning participant in the Blue Chip survey of forecasters. ${ }^{25}$ These daily forecasts allow us to see how Macroeconomic Advisers revised its real GDP forecast on the days of FOMC announcements, and compare those revisions to other days on which other economic data was released.

Second, we contacted the Chief Economist of every participating firm in the Blue Chip

\footnotetext{
${ }^{24}$ In June 2003, the unemployment rate was high despite the improving economy and the Fed cut the federal funds rate in response, but by less than the markets had expected, resulting in a surprise monetary policy tightening on the day of the FOMC announcement. The intuition is otherwise the same.

${ }^{25}$ Macroeconomic Advisers won Blue Chip's Lawrence Klein award for forecast accuracy in two different years, and was named by The Wall Street Journal as the most accurate macroeconomic forecaster of 2017.
} 
survey of forecasters, and asked them directly how they revise their real GDP, unemployment, and inflation forecasts in response to FOMC announcements.

\subsection{Macroeconomic Advisers GDP Tracking Estimates}

Macroeconomic Advisers (MA) is a private firm that has specialized in macroeconomic forecasting and analysis since 1982. In 2017 they were purchased by IHS Markit and are now known as Macroeconomic Advisers by IHS Markit. One of the many products they offer is a daily "GDP Tracking" estimate of current-quarter and next-quarter real GDP. Figure 3 provides an example of their current-quarter GDP Tracking estimate for 2011Q1 from the company's public blog in April 2011. ${ }^{26}$ Each month, the GDP Tracking report begins with a base Macroeconomic Advisers forecast for current-quarter real GDP growth. (Note that because real GDP for 2011Q1 is not released by the U.S. Bureau of Economic Analysis until the end of April 2011, it is still referred to as "current-quarter" GDP tracking by MA in April 2011.) That base forecast is then updated after every major macroeconomic data release that month. For example, when the monthly retail sales report from the U.S. Census Bureau for March 2011 came in substantially stronger than expected on April 13, 2011, MA revised up its forecast for 2011Q1 Personal Consumption Expenditures from 1.8 percent to 2.3 percent growth, implying an upward revision to their 2011Q1 real GDP growth forecast from 1.5 percent to 1.8 percent. They make analogous revisions for each of the other statistical releases listed in the figure. A quick glance over the statistics in Figure 3 reveals, however, that the FOMC announcement on April 27, 2011, is not listed. Apparently, the FOMC announcement on that date was not informative for MA's current-quarter real GDP forecast at that time.

Of course, one might worry that April 2011 was special, or that the FOMC announcement did affect MA's forecast of real GDP in future quarters, just not in the current quarter. To resolve these questions, we obtained copies of MA's current-quarter and next-quarter GDP Tracking forecasts for every month from January 2002 to December 2019. Over that 18-year period, we found that MA never revised its current-quarter or next-quarter GDP forecast in response to an FOMC announcement. This suggests that the Fed information effect is very small, at least for this one multiple-award-winning Blue Chip forecaster.

\footnotetext{
${ }^{26}$ See http://macroadvisers.blogspot.com/2011/04/q1-gdp-advance-estimate-is-18-02-pp.html.
} 
Figure 3: Macroeconomic Advisers 2011Q1 Real GDP Tracking Estimate, April 2011

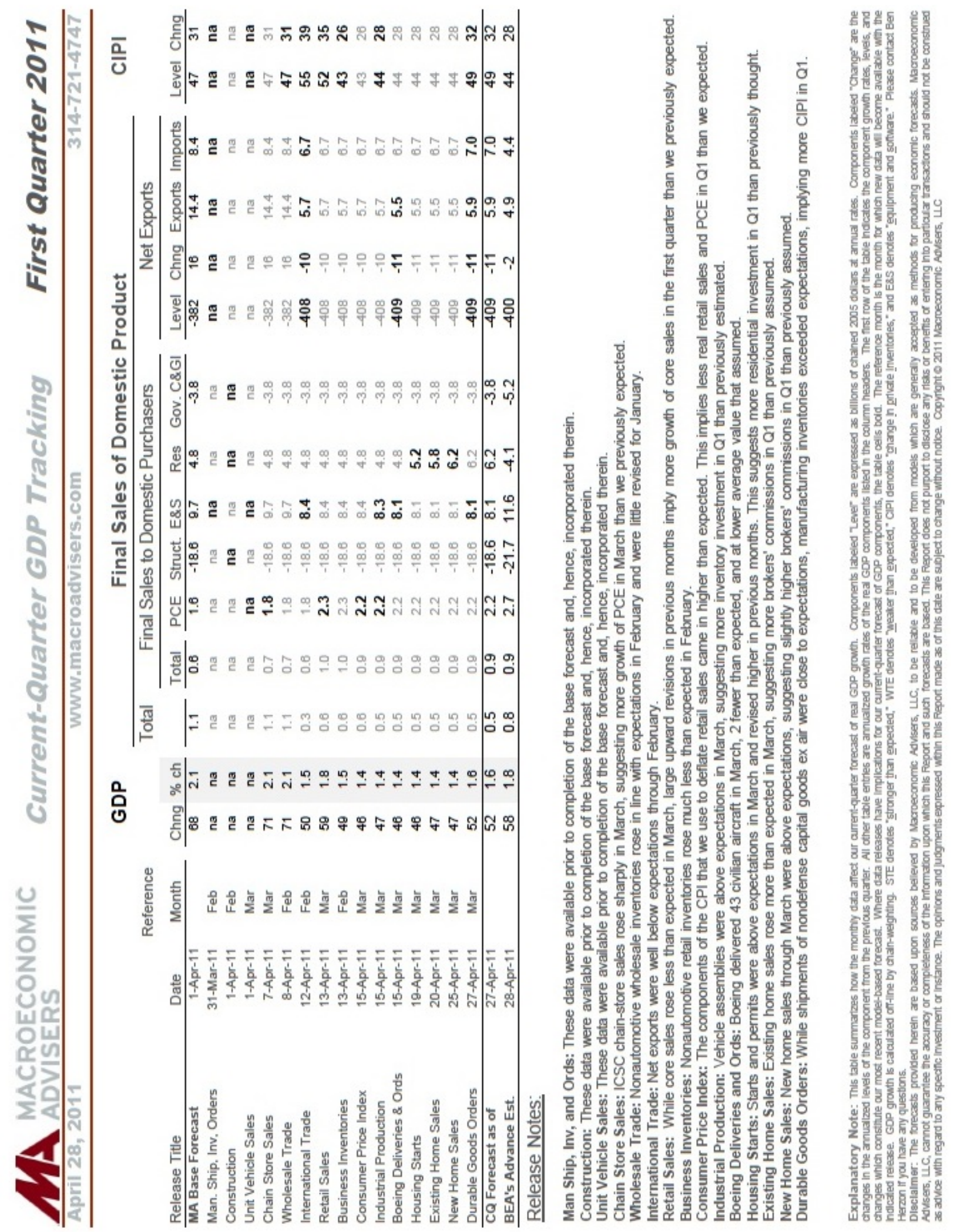

Source: Macroeconomic Advisers public blog, http://macroadvisers.blogspot.com/2011/04/ q1-gdp-advance-estimate-is-18-02-pp.html. 


\subsection{New Survey of Individual Blue Chip Forecasters}

One might still worry that Macroeconomic Advisers only reports daily GDP Tracking forecasts for the current and next quarters, or that MA is only one firm that is not representative of the Blue Chip panel of forecasters more generally. To address these concerns, we conducted our own survey of all 52 individual forecasting firms in the Blue Chip panel to ask them directly how they revise their forecasts in response to FOMC announcements.

We began by collecting the contact information for the Chief Economist for each of the 52 forecasting firms in the Blue Chip panel as of July 2019. The vast majority of these Chief Economists hold a Ph.D. from a highly ranked economics department, and several of them also have previous experience as economists working within the Federal Reserve System. ${ }^{27}$ Each Chief Economist typically oversees a team of several economists who assist with the forecast and other economic analysis provided to clients.

We sent each Chief Economist a brief email with our survey questions, provided in Appendix A. The goal of the survey was to find out whether Blue Chip forecasters revise their forecasts for real GDP, unemployment, and/or inflation in response to FOMC announcements and, if so, in which direction they revise those forecasts. Note that FOMC announcements consist of several components, including the federal funds rate decision itself, the FOMC statement, and sometimes a "dot plot" forecast of the FOMC's views regarding the appropriate path for the federal funds rate over the next two years, and an "SEP" Summary of the FOMC's own Economic Projections for GDP, unemployment, and inflation for the next two years. It's possible that the Blue Chip forecasters respond differently to different components of these FOMC announcements: for example, the change in the federal funds rate might be viewed as a "pure monetary policy" shock, while the FOMC statement might have a significant informational component, and the SEP might even be viewed as a "pure information" shock, since it explicitly communicates the FOMC's own forecast of macroeconomic variables. To allow for this kind of heterogeneity, we broke our survey question into four components, asking how the forecaster responds to each of: 1) changes in the federal funds rate, 2) the FOMC statement, 3) the "dot plot", and 4) the FOMC's SEP forecasts.

\footnotetext{
${ }^{27}$ For example, Lewis Alexander of Nomura, Seth Carpenter of UBS, Julia Coronado of MacroPolicy Perspectives, and Dean Maki of Point72 Asset Management each worked at the Federal Reserve Board for many years, while Carl Tannenbaum of Northern Trust worked at the Federal Reserve Bank of New York.
} 
Table 8: Blue Chip Forecaster Responses to FOMC Announcements: Results from Our Survey

\begin{tabular}{|c|c|c|c|}
\hline & \multicolumn{3}{|c|}{ Response to hawkish surprise in: } \\
\hline & fed funds rate & FOMC statement & "dot plot" \\
\hline Do not revise GDP forecast & 13 & 16 & 14 \\
\hline Revise GDP forecast downward & 18 & 15 & 18 \\
\hline $\begin{array}{l}\text { Revise GDP forecast, but direction } \\
\text { depends on other factors }\end{array}$ & 5 & 5 & 4 \\
\hline \multirow[t]{2}{*}{ Revise GDP forecast upward } & 0 & 0 & 0 \\
\hline & \multicolumn{3}{|c|}{$\begin{array}{l}\text { Response to FOMC's Summary of } \\
\text { Economic Projections (SEP) }\end{array}$} \\
\hline Do not revise GDP forecast & \multicolumn{3}{|c|}{24} \\
\hline $\begin{array}{l}\text { Revise GDP forecast towards SEP forecast } \\
\text { of GDP if substantially different }\end{array}$ & \multicolumn{3}{|c|}{4} \\
\hline $\begin{array}{l}\text { Use SEP to help forecast fed funds rate, } \\
\text { effect on GDP standard }\end{array}$ & \multicolumn{3}{|c|}{3} \\
\hline $\begin{array}{l}\text { Use SEP to help forecast fed funds rate, } \\
\text { effect on GDP depends on other factors }\end{array}$ & \multicolumn{3}{|c|}{1} \\
\hline $\begin{array}{l}\text { Revise GDP, but revision depends on } \\
\text { multiple factors }\end{array}$ & \multicolumn{3}{|c|}{2} \\
\hline
\end{tabular}

Number of private-sector forecasting firms (out of 36 total) reporting how they revise their GDP forecast in response to four main components of FOMC announcements: the federal funds rate, FOMC statement, FOMC "dot plot" projection of future federal funds rates, and FOMC "SEP" forecast of future real GDP, unemployment, and inflation. Two survey respondents did not provide answers for how they respond to the SEP forecasts. See text for details.

The results of our survey are summarized in Table 8. Overall, we received 36 responses out of 52 possible, a response rate of about 70 percent. Many forecasters noted that they rarely revised their forecast in response to FOMC announcements because the FOMC typically communicated the outcome of each meeting well in advance through speeches by FOMC members. Table 8 nevertheless reports in which direction they revise their GDP forecasts in those rare instances when the FOMC announcement is a surprise. Note that we focus on revisions to GDP forecasts in Table 8 for simplicity, but in every case survey respondents noted that they would revise inflation in the same direction and unemployment in the opposite direction to GDP, consistent with standard macroeconomic models; similarly, Table 8 reports 
results for hawkish surprises, but in every case respondents noted that they would revise in the opposite direction for dovish surprises. The top panel of Table 8 reports how respondents revised their GDP forecasts in response to a hawkish surprise in the federal funds rate, the FOMC statement, and the "dot plot" of federal funds rate projections. The bottom panel reports how respondents revised their GDP forecasts in response to the FOMC's SEP forecasts of GDP, unemployment, and inflation.

There are several important points to take away from Table 8. First, a large majority of the survey respondents, 24 out of 34 , do not revise their forecasts in response to the SEP. ${ }^{28}$ This observation directly contradicts the existence of a Fed information effect - after all, the FOMC is explicitly communicating its GDP, unemployment, and inflation forecasts to the public through the SEP and a large majority of the Blue Chip forecasters simply do not find that information useful. ${ }^{29}$

Second, Macroeconomic Advisers is not an outlier: many survey respondents do not revise their GDP (or unemployment or inflation) forecasts in response to any component of FOMC announcements. Of the 36 respondents, 13 do not revise their forecasts in response to changes in the funds rate, 16 do not revise in response to the FOMC statement, 14 do not revise in response to the dot plot, and 24 do not revise in response to the SEP (as mentioned above). The overlap across these groups is substantial, so there are 13 respondents who do not revise their forecasts in response to any component of FOMC announcements. This is surprising, given that standard macroeconomic models and VARs imply that tighter monetary policy should cause GDP to fall slightly over the next several quarters. Our survey respondents gave several different reasons for their unresponsiveness to FOMC announcements: Some forecasters said that the announcements have not been a surprise for many, many years and are just not informative about monetary policy, relative to FOMC member speeches and press

\footnotetext{
${ }^{28}$ Two of our survey respondents did not report how they revise their forecasts in response to the SEP, leaving us with 34 observations instead of 36 for this question.

${ }^{29}$ For example, one forecaster commented that "I trust my outlook more than the Fed's... Their forecasting ability is pretty poor." Another noted, "My view is that the Fed does not have superior information... The FOMC forecast tends to be off by a lot." Other forecasters said, "We tend to find that the Fed has no better information advantage over economists like myself... In fact, what we have found many times is Fed forecasts (per the SEP) tend to be somewhat stale," and "I would be responding to the change in the policy outlook, not to the possibility that the Fed 'knew' something that I did not." Even one of the respondents who does revise their GDP forecast in response to the SEP noted that "We would not be updating our forecasts because we think the SEP forecasts are good. But if we think they signal something about future policy and portend a market shock then we might change some forecasts in anticipation of that."
} 
conferences. ${ }^{30}$ Other forecasters said that if they were surprised by an FOMC announcement, then they viewed that surprise as an FOMC "mistake" that the FOMC would later have to unwind, resulting in no net change to the GDP forecast. ${ }^{31}$ A few forecasters said that they could find only very small effects of changes in interest rates on GDP, so that changes in the federal funds rate or dot plot just didn't have any significant effect on their forecast. ${ }^{32}$

The third main point to take away from Table 8 is that, of our survey respondents who do revise their forecasts in response to FOMC announcements, the vast majority (18 out of 23) revise those forecasts in the standard way - that is, a hawkish monetary policy surprise causes them to revise their GDP forecast downward. In contrast, none of our survey respondents said that they would revise their GDP forecast upward, directly contradicting the predictions in Campbell et al. (2012) and Nakamura and Steinsson (2018). However, five forecasters did say that their GDP forecast revision would depend on other factors. ${ }^{33}$ Although this last group of 5 forecasters does allow for the existence of an information effect, and one of those respondents even explicitly raised that possibility, those forecasters are vastly outnumbered (by about 18-5 or 31-5) by respondents who say they simply do not revise their forecasts in the way that the Fed information effect would require. In fact, several of these latter forecasters explicitly commented on the Fed's SEP forecasts as being "somewhat stale", "pretty poor", "off by a lot", or "not...good" (see footnote 29). Given this huge imbalance, it's essentially impossible for the Blue Chip consensus forecast to contain a significant Fed information effect.

\footnotetext{
${ }^{30}$ For example, one forecaster said, "I have not been surprised by an FOMC announcement since well before 2008 (including January 2008 [a 75bp intermeeting interest rate cut])." A second noted, "In the end, we are likely to get more information from speeches and press conferences than we are from the statement, the decision, or the dots. So by the time we get those things, it tends to be relatively 'old news', if you will." A third stated, "I make my forecasts based on the data, not Fed assumptions. I haven't been surprised by them in a very long time."

${ }^{31}$ One forecaster explained, "My view is that the Fed does not have superior information. As a result, over time, if my forecast is right and the Fed's action at some meeting is wrong, they will come to see the forecast as 'true' and adjust policy in response." A second stated, "If we think the Fed is about to make a decision that is inconsistent with our expected outlook, we often think that will lead to a change in financial conditions that will in turn push the Fed back to where we think is appropriate for the economy."

${ }^{32}$ For example, "I could never find an effect of interest rates on any component of investment except residential [which was too small to have a significant effect on the GDP forecast]."

${ }^{33}$ For example, one forecaster said "There is no simple answer to that question, it depends on what else is happening." Another stated that they would ask themselves, "Does the Fed know something?" A third forecaster said, "If the Fed was particularly concerned with maintaining price stability or...curbing rising inflation expectations then we might lower our GDP forecast... [but] If such a policy stance reduced the volatility in inflation or inflation expectations [as measured by TIPS vs. nominal Treasuries] then we might raise our GDP forecast as a result."
} 


\section{Forecast Accuracy: Fed vs. Blue Chip}

To motivate the existence of a Fed information effect, many authors have argued that the Fed produces better forecasts than the private sector. For example, Romer and Romer (2000) note that "the Federal Reserve commits far more resources to forecasting than even the largest commercial forecasters. As a result, it is able to produce superior forecasts from publicly available information," (p. 437). However, Faust et al. (2004a) point out that markets aggregate information, as discussed in detail by Hayek (1945) and Grossman (1981, 1989), and there are very large, very liquid markets that are closely tied to interest rate and inflation forecasts, such as the markets for nominal and real Treasury bonds, inflation swaps, and interest rate futures, options, and swaps. Private-sector forecasters follow these markets closely, so it would be very surprising if the Fed's forecasts of these variables was substantially better than the private sector's. Although the market for GDP forecasts is not as large or liquid as those for interest rate and inflation forecasts, GDP forecasts are nevertheless closely tied to the future paths of interest rates, stock prices, and credit spreads, so again it would be surprising if the Fed's forecast for GDP was substantially better than the private sector's. In other words, the information aggregation taking place in the markets should be substantial, and the private sector as a whole devotes vastly more resources to forecasting than does the Federal Reserve.

In this section, we conduct a detailed comparison of Blue Chip (BC) vs. Federal Reserve forecasts of unemployment, GDP, and inflation. The Fed's internal forecasts are produced as part of the "Greenbook" a few days prior to each scheduled FOMC meeting, and those Greenbook (GB) forecasts are made available to the public with a five-year lag. ${ }^{34}$ We have data for the GB and BC forecasts from January 1980 to December 2013, for a total of 274 forecast dates.

To compare the BC forecasts to the GB forecasts, we need to deal with the fact that the frequency and publication dates of these two forecast series differ: the BC survey is conducted monthly at the beginning of each month, while the GB forecasts are made eight times per year before each scheduled FOMC meeting, which can occur at any point within a month. For our baseline results, below, we match each GB forecast with whichever BC forecast is the closest;

\footnotetext{
${ }^{34}$ Beginning in June 2010, the Fed's separate "Greenbook" and "Bluebook" documents were combined into a single "Tealbook". For simplicity, we use the term "Greenbook forecast" to refer to the Fed's internal forecast throughout our sample, even though the Greenbook was replaced by the Tealbook from June 2010 onward.
} 
this BC forecast could have been made either before or after the corresponding GB forecast, depending on whether that particular GB forecast was made closer to the beginning or the end of the month. As a result, the BC forecasts have a slight informational advantage over the GB for 124 of the GB forecast dates, whereas the GB forecasts have a slight informational advantage over $\mathrm{BC}$ for the other 150 forecast dates. In the Appendix, we report results for the alternative schemes of always comparing the GB forecast to the previous BC forecast (giving the GB an informational advantage), or always comparing the GB forecast to the next BC forecast (giving $\mathrm{BC}$ an informational advantage).

We obtain the corresponding macroeconomic data releases from the St. Louis Fed's FRED database. For real GDP growth and CPI inflation, forecasts are made for quarterly growth rates at an annualized rate, whereas the unemployment rate forecasts are made for the quarterly average value. We consider forecast horizons of zero (i.e., nowcasts) to three quarters ahead, as well as forecasts of the average realized values over these four quarters.

We estimate "encompassing regressions" similar to those of Romer and Romer (2000),

$$
X_{t+h}=\alpha+\beta \hat{X}_{t+h \mid t}^{G B}+\gamma \hat{X}_{t+h \mid t}^{B C}+\varepsilon_{t+h},
$$

where the realized value of a macroeconomic variable $X$ in quarter $t+h$ is regressed on both the GB and BC forecasts of that variable, $\hat{X}_{t+h \mid t}^{G B}$ and $\hat{X}_{t+h \mid t}^{B C}$, at time $t$ to see which forecast receives more weight, where $h$ denotes the forecast horizon in quarters. ${ }^{35}$ However, Sims (2002) cautions against the use of encompassing regressions in this context, because the forecasts are serially correlated and have very similar information content; instead, Sims recommends focusing on accuracy measures for each forecast considered separately. Thus, we also calculate root-mean-squared errors (RMSEs) for each of the BC and GB forecasts separately, and perform a Diebold and Mariano (1995) test for equal predictive accuracy.

The results are reported in Table 9. For comparability to previous tables, we focus on the period since 1990 in Table 9, but results for the longer, 1980-2013 sample are reported in

\footnotetext{
${ }^{35}$ To conduct statistical inference we need to account for serial correlation in the forecast errors due to the overlap in the observations, which depends on the forecast horizon. Like Romer and Romer (2000), we use the Hansen-Hodrick long-run covariance estimator and, because of our sample frequency, we use $2(h+1)$ lags, where $h$ is the forecast horizon in quarters (and we set $h=3$ when we forecast the average over 0-3 quarters). In quarterly data, the overlap would induce serial correlation in the residuals up to order $h+1$; our sample of GB forecast dates has eight observations per year (the number of FOMC meetings), which implies serial correlation up to order $2(q+1)$.
} 
Table 9: Comparison of Greenbook and Blue Chip Forecasts

\begin{tabular}{|c|c|c|c|c|c|c|c|}
\hline \multirow{2}{*}{$\begin{array}{c}\text { Horizon } \\
\text { (quarters) }\end{array}$} & \multicolumn{3}{|c|}{ RMSEs } & \multicolumn{4}{|c|}{ Encompassing Regressions } \\
\hline & GB & $\mathrm{BC}$ & $H_{0}: G B=B C$ & GB & $\mathrm{BC}$ & $R^{2}$ & $H_{0}: G B=B C$ \\
\hline \multicolumn{8}{|c|}{ (A) Unemployment rate } \\
\hline 0 & 0.18 & 0.17 & .412 & $\begin{array}{l}0.41^{* * *} \\
(.124)\end{array}$ & $\begin{array}{c}0.58^{* * *} \\
(.124)\end{array}$ & .99 & .478 \\
\hline 1 & 0.34 & 0.34 & .831 & $\begin{array}{l}0.60^{* *} \\
(.247)\end{array}$ & $\begin{array}{c}0.39 \\
(.254)\end{array}$ & .96 & .667 \\
\hline 2 & 0.54 & 0.53 & .842 & $\begin{array}{c}0.45 \\
(.336)\end{array}$ & $\begin{array}{c}0.53 \\
(.345)\end{array}$ & .90 & .906 \\
\hline 3 & 0.73 & 0.73 & .952 & $\begin{array}{c}0.47 \\
(.401)\end{array}$ & $\begin{array}{c}0.49 \\
(.402)\end{array}$ & .80 & .979 \\
\hline $0-3$ avg. & 0.42 & 0.42 & .923 & $\begin{array}{c}0.50 \\
(.315)\end{array}$ & $\begin{array}{c}0.48 \\
(.318)\end{array}$ & .93 & .974 \\
\hline \multicolumn{8}{|c|}{ (B) Real GDP growth } \\
\hline 0 & 1.96 & 1.97 & .741 & $\begin{array}{c}0.55^{*} \\
(.304)\end{array}$ & $\begin{array}{c}0.51 \\
(.467)\end{array}$ & .45 & .967 \\
\hline 1 & 2.44 & 2.32 & .030 & $\begin{array}{c}-0.24 \\
(.348)\end{array}$ & $\begin{array}{l}1.45^{* *} \\
(.637)\end{array}$ & .22 & .079 \\
\hline 2 & 2.46 & 2.49 & .739 & $\begin{array}{c}0.76 \\
(.377)\end{array}$ & $\begin{array}{c}-0.13 \\
(.617)\end{array}$ & .09 & .322 \\
\hline 3 & 2.55 & 2.52 & .710 & $\begin{array}{c}0.76 \\
(.476)\end{array}$ & $\begin{array}{c}-0.98 \\
(.807)\end{array}$ & .03 & .138 \\
\hline $0-3$ avg. & 1.64 & 1.60 & .447 & $\begin{array}{c}0.20 \\
(.375)\end{array}$ & $\begin{array}{c}0.77 \\
(.499)\end{array}$ & .23 & .485 \\
\hline \multicolumn{8}{|c|}{ (C) CPI inflation } \\
\hline 0 & 0.89 & 1.15 & .012 & $\begin{array}{l}0.92^{* * *} \\
(.107)\end{array}$ & $\begin{array}{c}0.09 \\
(.118)\end{array}$ & .81 & .000 \\
\hline 1 & 2.01 & 2.07 & .554 & $\begin{array}{l}0.85^{* * *} \\
(.315)\end{array}$ & $\begin{array}{r}-0.33 \\
(.387)\end{array}$ & .14 & .077 \\
\hline 2 & 1.92 & 1.80 & .092 & $\begin{array}{c}-0.12 \\
(.322)\end{array}$ & $\begin{array}{c}0.57 \\
(.402)\end{array}$ & .03 & .318 \\
\hline 3 & 1.96 & 1.87 & .191 & $\begin{array}{c}-0.20 \\
(.499)\end{array}$ & $\begin{array}{c}0.52 \\
(.586)\end{array}$ & .01 & .503 \\
\hline $0-3$ avg. & 1.13 & 1.05 & .242 & $\begin{array}{c}0.24 \\
(.343)\end{array}$ & $\begin{array}{c}0.34 \\
(.405)\end{array}$ & .19 & .899 \\
\hline
\end{tabular}

Comparison of forecast accuracy for Federal Reserve Greenbook ("GB") and Blue Chip ("BC") forecasts from 1990-2013 (192 observations). Root-mean-squared errors (RMSEs) are reported for each forecast, with a DieboldMariano $p$-value for the null hypothesis that the forecasts are equally accurate. For encompassing regressions, the realized value for each macro series is regressed on a constant and both the GB and BC forecasts, and the table reports the coefficients, the regression $R^{2}$, and $p$-value for the null hypothesis that the coefficients are equal. Hansen-Hodrick standard errors with $2(h+1)$ lags for forecast horizon $h$ are reported in parentheses; ${ }^{* * *}$, ${ }^{* *}$, and ${ }^{*}$ denote statistical significance at the $1 \%, 5 \%$, and $10 \%$ levels, respectively. See text for details. 
Appendix Table B.4 and are very similar. The top panel compares the GB and BC forecasts for the unemployment rate, the middle panel for real GDP growth, and the bottom panel for CPI inflation. ${ }^{36}$ The first set of columns compares the RMSEs for the two forecasts, including a test of the null hypothesis that the two RMSEs are equal. The second set of columns reports the encompassing regression results, including a test of the null hypothesis that the two coefficients are equal.

The main conclusion from Table 9 is that neither the Fed nor the Blue Chip had significantly better forecasts over this sample. For the unemployment rate, in the top panel, the two sets of forecasts are essentially identical in terms of their RMSEs, and the encompassing regressions put essentially equal weight on both forecasts. For real GDP, in the middle panel, the BC forecast has lower RMSE than GB at horizons of 1 and 3 quarters and for the 0-3 quarter average (and this difference is statistically significant at the 1-quarter-ahead horizon). At other horizons, the BC and GB forecasts are essentially the same. The encompassing regression results tell a similar story. For CPI inflation, in the bottom panel, the GB has lower RMSE than BC for the current and 1-quarter-ahead horizons (and the difference is statistically significant for the current quarter), but the BC forecast has lower RMSE than GB at the 2- and 3-quarter-ahead horizons and for the 0-3 quarter average (and the difference is marginally significant at the $10 \%$ level for the 2-quarter-ahead horizon). Overall, the BC and GB forecasts are very similar and perform very comparably. Results in Appendix Table B.4 going back to 1980 lead to very similar conclusions.

These results suggest that the Fed does not have a systematic forecasting advantage over the private sector. Although Romer and Romer (2000) found that the Fed's inflation forecasts outperformed those of the private sector, their sample covered only 12 years, from 1980-1991, a large part of which was dominated by the Volcker disinflation in the early 1980s. Our sample in Table 9 is twice as long, is more recent, and excludes the Volcker disinflation, which Faust et al. (2004a) showed was crucial for the Romers' results. ${ }^{37}$ Other recent studies also find that, if the Fed ever had a forecasting advantage, it has eroded over time (Gamber and Smith,

\footnotetext{
${ }^{36}$ The $R^{2}$ for the unemployment rate are naturally much higher (and RMSEs much lower) than for the other series, because this data series is highly persistent and therefore easier to forecast over the next few quarters.

${ }^{37}$ Sims (2002) also finds that the Fed predicted future inflation more accurately than the Survey of Professional Forecasters, but his sample is only slightly longer than the Romers' and also includes the Volcker disinflation.
} 
2009; Paul, 2019; Hoesch et al., 2020).

Our finding that the GB and BC forecasts have very similar accuracy casts doubt on one of the main arguments for the Fed information effect, that the Fed's macroeconomic forecasts are materially better than those of the private sector.

\section{Learning about the Monetary Policy Rule}

Many recent studies have used high-frequency changes in interest rates around FOMC announcements to estimate the effects of monetary policy on financial markets or the real economy(e.g., Kuttner, 2001; Cochrane and Piazzesi, 2002; Faust et al., 2004b; Gürkaynak et al., 2005a,b; Bernanke and Kuttner, 2005; Campbell et al., 2012; Gertler and Karadi, 2015; Nakamura and Steinsson, 2018). The typical assumption in these studies is that a high-frequency surprise in interest rates represents an exogenous monetary policy shock $\varepsilon_{t}$, in the notation of equation (1). In contrast, our empirical results above showed that these high-frequency surprises are predictable ex post with information available prior to the FOMC announcement. In this section, we present a simple model that illustrates how learning about the monetary policy rule can lead to precisely this type of predictability. In addition, we use the model to discuss the practical implications of the Fed response to news channel for measuring the effects of monetary policy on financial markets and the economy.

\subsection{A Simple Model with Imperfect Information}

There are two agents in the economy: the private sector and the central bank. The output gap $x_{t}$ is observed by all agents at each time $t$, and follows the exogenous $\mathrm{AR}(1)$ process

$$
x_{t}=\rho_{x} x_{t-1}+\eta_{t}
$$

where $\rho_{x} \in[0,1)$ and $\eta_{t}$ is an exogenous shock with $\eta_{t} \sim$ i.i.d. $N\left(0, \sigma_{\eta}^{2}\right)$. Note that, for simplicity, we assume that the output gap $x_{t}$ evolves exogenously and doesn't depend on the interest rate or any other factors.

In each period $t$, after $x_{t}$ is observed, the central bank sets the interest rate $i_{t}$ according 
to a linear monetary policy rule,

$$
i_{t}=a x_{t}+\varepsilon_{t}
$$

where $a>0$ denotes the central bank's responsiveness to the output gap, and $\varepsilon_{t}$ is an exogenous shock with $\varepsilon_{t} \sim$ i.i.d. $N\left(0, \sigma_{\varepsilon}^{2}\right)$.

The parameter $a$ is known by the central bank but is unknown and unobserved by the private sector; thus, the private sector does not have full information. All other parameters of the model are known by all agents. The variables $x_{t}$ and $i_{t}$ are observed by all agents in each period $t$, but $\varepsilon_{t}$ is never observed by the private sector (or else $a$ could be backed out exactly). Let $\mathcal{H}_{t}=\left\{i_{t}, x_{t}, i_{t-1}, x_{t-1}, \ldots\right\}$ denote the history of economic data up until time $t$.

In each period, the private sector starts with prior beliefs $a \sim N\left(\hat{a}_{t}, \sigma_{a_{t}}^{2}\right)$, with moments $\hat{a}_{t}=E\left[a \mid \mathcal{H}_{t-1}\right]$ and $\sigma_{a_{t}}^{2}=\operatorname{Var}\left[a \mid \mathcal{H}_{t-1}\right]$. Once $x_{t}$ is realized, but before the central bank announces $i_{t}$, the private sector's expectations for current and future interest rates, $i_{t+j}$, $j=0,1,2, \ldots$, are

$$
E\left[i_{t+j} \mid x_{t}, \mathcal{H}_{t-1}\right]=E\left[a x_{t+j} \mid x_{t}, \mathcal{H}_{t-1}\right]=\hat{a}_{t} \rho_{x}^{j} x_{t} .
$$

After the central bank announces $i_{t}$, the private sector is surprised by the amount

$$
m p s_{t} \equiv i_{t}-E\left[i_{t} \mid x_{t}, \mathcal{H}_{t-1}\right]=\left(a-\hat{a}_{t}\right) x_{t}+\varepsilon_{t} .
$$

In response to the monetary policy surprise $m p s_{t}$, the private sector optimally updates its beliefs about $a$. Bayesian updating implies that, after observing $i_{t}$, the private sector's posterior beliefs are

$$
E\left[a \mid \mathcal{H}_{t}\right]=\hat{a}_{t}+\theta \frac{1}{x_{t}} m p s_{t}
$$

where $\theta \equiv \frac{x_{t}^{2} \sigma_{a_{t}}^{2}}{x_{t}^{2} \sigma_{a_{t}}^{2}+\sigma_{\varepsilon}^{2}}$. Similarly, the private sector updates its forecast for the future path of interest rates $i_{t+j}, j=1,2, \ldots$, with revisions

$$
\begin{aligned}
E\left[i_{t+j} \mid \mathcal{H}_{t}\right]-E\left[i_{t+j} \mid x_{t}, \mathcal{H}_{t-1}\right] & =E\left[a x_{t+j} \mid \mathcal{H}_{t}\right]-E\left[a x_{t+j} \mid x_{t}, \mathcal{H}_{t-1}\right] \\
& =\left(E\left[a \mid \mathcal{H}_{t}\right]-\hat{a}_{t}\right) \rho_{x}^{j} x_{t} \\
& =\rho_{x}^{j} \theta \text { mps s}_{t} .
\end{aligned}
$$


Thus, in response to a monetary policy surprise at time $t$, the private sector passes a fraction $\theta$ of this surprise through to expected future interest rates, and revises its interest rate forecasts by an amount that diminishes at the rate $\rho_{x}$.

Obviously, in this simple environment with a fixed value of $a$, the private sector's beliefs would converge to the true value of $a$ asymptotically, but at time $t$, the private sector has only the estimate $\hat{a}_{t}$. We don't take a stand on why $a$ is unknown, but there are several possible motivations: First, it takes time to learn the true value of $a$, so private sector uncertainty may simply reflect that the true value has not yet been learned. Second, a may change over time (due to changes in the Fed chair or Fed policy), which would prevent the private sector from ever learning $a$ to a high degree of accuracy. Third, in the case of a nonlinear monetary policy rule, as in equation (1), any nonlinearities may be especially difficult to learn and may prevent the private sector from knowing how the Fed will respond to extreme values of $x_{t}$ (because extreme values occur so rarely). Regardless of the source of uncertainty about $a$, our simple model gives insights into the effects of monetary policy surprises, which we turn to next.

\subsection{Implications for High-Frequency Regressions}

The simple model described above helps to highlight several important points. First, the monetary policy surprise in (14) could be due either to a traditional, exogenous monetary policy shock $\varepsilon_{t}$, or to the private sector not knowing the central bank's monetary policy rule - a difference between $a$ and $\hat{a}_{t}$. If $a$ is known (so that $\hat{a}_{t}=a$ always holds, and $\theta=0$ ), then $m p s_{t}=\varepsilon_{t}$ every period and the monetary policy surprise is completely unpredictable. However, if the private sector does not know the true policy rule $\left(\hat{a}_{t} \neq a\right)$, then the monetary policy surprise $m p s_{t}$ can be correlated with $x_{t}$ ex post, even though it is unpredictable ex ante. ${ }^{38}$ For example, if $\hat{a}_{t}<a$ for several periods, then the monetary policy surprise $m p s_{t}$ will be positively correlated with $x_{t}$ ex post over that sample, as was the case in our empirical analysis above. ${ }^{39}$ Thus, our model illustrates that, due to learning by the private sector about

\footnotetext{
${ }^{38}$ To see that the policy surprise is unpredictable ex ante, note that $E\left[m p s_{t} \mid x_{t}, \mathcal{H}_{t-1}\right]=0$, meaning that the private sector's forecast of $m p s_{t}$ cannot be improved using any variable observed before $i_{t}$ is determined.

${ }^{39}$ For example, the Fed under Greenspan may have responded to output by more than it did under Volcker; the Fed under Bernanke may have responded to output by more than under Greenspan; and the Fed under Yellen may have responded to output by more than under Bernanke. If this were the case, the private sector's estimate of $a_{t}$ is likely to have been persistently less than $a$ throughout our sample.
} 
the policy rule, monetary policy surprises can be predictable ex post, even if forecasts about $i_{t}$ are rational and optimal ex ante and there are no risk premia.

A second key takeaway from the model is that an exogenous shock $\varepsilon_{t}$ has exactly the same effects on current and future interest rates as a monetary policy surprise $m p s_{t}$ more generally. This can be seen in equation (17), in which interest rate expectations respond to $m p s_{t}$ (and not to $\varepsilon_{t}$ separately), and in equation (14), in which the effects of an exogenous shock $\varepsilon_{t}$ manifest themselves entirely through $m p s_{t}$, because the private sector never observes $\varepsilon_{t}$ by itself. Thus, if an econometrician uses high-frequency data on monetary policy surprises $m p s_{t}$ to estimate the effects of those surprises on the yield curve (or other asset prices), then those effects are also representative of the effects of an exogenous monetary policy shock $\varepsilon_{t}$ on the yield curve (or other asset prices).

In other words, even though the high-frequency monetary policy surprises $m p s_{t}$ may be correlated with macroeconomic data $x_{t}$ ex post, they still can be used, without adjustment, to estimate the effects of an exogenous change in monetary policy $\varepsilon_{t}$ on asset prices in a narrow window of time around an FOMC announcement. This implies that the high-frequency empirical estimates in Kuttner (2001), Gürkaynak et al. (2005a,b), Bernanke and Kuttner (2005), and others reliably answer the question: What are the effects of an exogenous change in monetary policy $\left(\varepsilon_{t}\right)$ on the yield curve, the stock market, and other asset prices? ${ }^{40}$

\subsection{Implications for High-Frequency Identification of VARs}

In addition to the high-frequency financial market regressions discussed above, a second important application of high-frequency monetary policy surprises is to the identification of the effects of monetary policy shocks in monthly VARs (e.g., Cochrane and Piazzesi, 2002; Faust et al., 2004b; Gertler and Karadi, 2015; Nakamura and Steinsson, 2018). In order to be a valid external instrument for the monthly monetary policy shock in a VAR, the high-frequency surprise $m p s_{t}$ must satisfy two conditions: an instrument relevance condition and an instrument exogeneity condition (e.g., Stock and Watson, 2012). The first condition is clearly satisfied,

\footnotetext{
${ }^{40}$ Of course, one can also orthogonalize the monetary policy surprises $m p s_{t}$ by regressing them on $x_{t}$ and taking the residuals, thus projecting out the ex post correlation of $m p s_{t}$ with $x_{t}$. This provides a more accurate estimate of the exogenous component $\varepsilon_{t}$ of the monetary policy surprises $m p s_{t}$, but it actually reduces the efficiency of the high-frequency regressions (17), because yield changes are related to the full monetary policy surprise $m p s_{t}$ and not just the exogenous component $\varepsilon_{t}$.
} 
because the high-frequency monetary policy surprise $m p s_{t}$ includes the exogenous FOMC announcement day shock $\varepsilon_{t}{ }^{41}$

The more difficult question is whether the high-frequency monetary policy surprise $m p s_{t}$ is orthogonal to the other, non-monetary structural shocks in the monthly VAR, such as an exogenous shock to output. According to our simple model above, $m p s_{t}$ is correlated with the output gap $x_{t}$ ex post, as in equation (14). Thus, under the timing assumptions of the simple model - where the central bank sets $i_{t}$ as a function of the output gap $x_{t}$-a structural output shock is correlated with $m p s_{t}$ and the instrument exogeneity condition is violated. In this case, researchers would need to "project out" the (ex post) correlation by regressing $m p s_{t}$ on macroeconomic data (here, $x_{t}$ ) and using the residuals as the external instrument for identification, exactly as suggested by Miranda-Agrippino and Ricco (2020).

However, there are cases where no adjustment of the high-frequency monetary policy surprise $m p s_{t}$ is necessary. For example, if the central bank observes the state of the economy with a one-month lag, then it sets the interest rate in month $t$ as a function of the output gap in month $t-1$ :

$$
i_{t}=a x_{t-1}+\varepsilon_{t} .
$$

As a result, the monetary policy surprise is given by

$$
m p s_{t}=\left(a-\hat{a}_{t}\right) x_{t-1}+\varepsilon_{t}
$$

rather than (14). Under this timing assumption, the monetary policy surprise $m p s_{t}$ is still relevant (as it contains $\varepsilon_{t}$ ), but now also satisfies the exogeneity condition, because $m p s_{t}$ is orthogonal to all non-monetary structural shocks in month $t$. In this case, there is no need to project out any correlation of $m p s_{t}$ with the macroeconomic data; the unadjusted monetary policy surprises $m p s_{t}$ can be used as an external instrument for identification in the VAR. ${ }^{42}$

Either of the timing assumptions above could be operative in practice. The Fed responds

\footnotetext{
${ }^{41}$ The high-frequency FOMC announcement day shock $\varepsilon_{t}$ should be an important component of the news about monetary policy in month $t$, even though it is not necessarily equal to the monthly monetary policy shock in the VAR. Equality may fail if there is other news about monetary policy that arrives over the course of the month, such as through speeches by the Fed chair or other FOMC members, which may convey information about monetary policy to the markets on days other than FOMC announcement dates.

${ }^{42}$ Although note that there is nothing wrong with orthogonalizing the monetary policy surprises by projecting out correlations with current and lagged macroeconomic data, as suggested by Miranda-Agrippino and Ricco (2020); it is just not necessary to do so.
} 
to publicly available information about the state of the economy, but some of that information (such as nonfarm payrolls) is observed with a one-month lag, while other information (such as the stock market) is observed within the month (up to the day before the FOMC announcement). Our empirical estimates in Section 3, above, suggest that the Fed responds to both types of information. In order for the high-frequency monetary policy surprise $m p s_{t}$ to be a valid external instrument, the correlation with the time-t information in the VAR (such as the stock market) would have to be projected out.

Our simple learning model above provides a useful framework for thinking about the Fed response to news channel and its implications for applied work using high-frequency monetary policy surprises. Although the model makes several simplifying assumptions - such as a single state variable, linear monetary policy rule, and exogeneity of the state variable - these should have only minor effects on the conclusions. Finally, although we assumed a complete absence of a Fed information effect in the model, in line with our empirical results, one could extend it along the lines of Nakamura and Steinsson (2018) to incorporate such an effect. However, the Fed response to news channel is sufficient by itself to explain all of our empirical findings.

\section{Conclusions}

We review and investigate the "Fed information effect" and find little or no support for it in the data. First, we show that standard Blue Chip forecast regressions along the lines of Campbell et al. (2012) and Nakamura and Steinsson (2018) are sensitive to sample period and to the variable being forecast (unemployment, GDP, or inflation). If the Fed information effect were true, this would suggest that the information content of FOMC announcements changes over time, sometimes being informative about GDP but not unemployment or inflation, other times being informative about unemployment but not GDP or inflation, etc. Instead of a Fed information effect, we show that these results are consistent with a "Fed response to news" channel, in which both the Fed and private sector forecasters are responding to publicly available economic news that is released in the runup to FOMC announcements.

We then present substantial new evidence that distinguishes between the Fed information effect and the Fed response to news channels. First, we show that economic news released in the days between the Blue Chip survey and the FOMC announcement is an omitted variable 
in standard information effect regressions, and that this omitted variable is correlated with the monetary policy surprise. Controlling for this economic news renders the statistical relationship between policy surprises and Blue Chip forecast revisions statistically insignificant and reverses its sign back to what would be predicted by standard macroeconomic models.

Second, we show that FOMC monetary policy surprises have a strong, highly statistically significant negative effect on stock prices in the 30-minute window surrounding FOMC announcements; moreover, this effect even more negative for the most influential dates in the traditional Blue Chip information effect regressions (discussed above). These findings suggest that the stock market does not view FOMC announcements as having a significant information component, but they are consistent with the Fed response to news channel.

Third, we conducted our own survey of all 52 forecasters in the Blue Chip panel, and asked them directly how they revise their GDP, unemployment, and inflation forecasts in response to FOMC announcements. According to our survey, the vast majority of Blue Chip forecasters either do not revise their GDP, unemployment, and inflation forecasts, or revise them in the standard (i.e., non-information-effect) direction. This is direct evidence, from the Blue Chip forecasters themselves, that there is little or no Fed information effect. In contrast, our Fed response to news channel is consistent with their responses.

We conclude that the Fed and private sector forecasters are both simply responding to the same public news released in the days and weeks leading up to each FOMC announcement, and that there is little if any role for a Fed information effect.

As a check on our results, we also conducted a detailed comparison of Blue Chip and Federal Reserve internal ("Greenbook") forecasts and verified that those forecasts are very similar, with neither forecast outperforming the other.

Finally, we present a simple model of the Fed response to news channel that demonstrates that high-frequency monetary policy surprises can be used in standard high-frequency regressions, without correction or adjustment, to estimate the effects of monetary policy on the yield curve and other asset prices. For high-frequency identification of the effects of monetary policy in a VAR, correcting the high-frequency monetary policy surprises for the Fed response to news channel may be necessary in some cases, depending on the variables and timing assumptions in the VAR. 


\section{References}

Andersen, Torben and Tim Bollerslev (1998) "Deutsche Mark-Dollar Volatility: Intraday Activity Patterns, Macroeconomic Announcements, and Longer Run Dependencies," Journal of Finance, Vol. 53, pp. 219-265.

Barro, Robert J. (1976) "Rational Expectations and the Role of Monetary Policy," Journal of Monetary Economics, Vol. 2, pp. 1-32.

Barro, Robert J. and David B. Gordon (1983) "Rules, Discretion and Reputation in a Model of Monetary Policy," Journal of Monetary Economics, Vol. 12, pp. 101-121.

Bernanke, Ben S. and Kenneth N. Kuttner (2005) "What Explains the Stock Market's Reaction to Federal Reserve Policy?" Journal of Finance, Vol. 60, pp. 1221-1257.

Brave, Scott A., R. Andrew Butters, and David Kelley (2019) "A new "big data" index of U.S. economic activity," Economic Perspectives, Federal Reserve Bank of Chicago.

Campbell, Jeffrey R., Charles L. Evans, Jonas D. M. Fisher, and Alejandro Justiniano (2012) "Macroeconomic Effects of Federal Reserve Forward Guidance," Brookings Papers on Economic Activity, pp. 1-54.

Christiano, Lawrence J., Martin Eichenbaum, and Charles L. Evans (1996) "The Effects of Monetary Policy Shocks: Evidence From the Flow of Funds," The Review of Economics and Statistics, Vol. 78, pp. 16-34.

Cieslak, Anna (2018) "Short-rate expectations and unexpected returns in treasury bonds," Review of Financial Studies, Vol. 31, pp. 3265-3306.

Cieslak, Anna and Andreas Schrimpf (2019) "Non-Monetary News in Central Bank Communication," Journal of International Economics, forthcoming.

Cochrane, John H. and Monika Piazzesi (2002) "The Fed and Interest Rates-A HighFrequency Identification," American Economic Review, Vol. 92, pp. 90-95.

D'Amico, Stefania and Mira Farka (2011) "The Fed and the Stock Market: An Identification Based on Intraday Futures Data," Journal of Business and Economic Statistics, Vol. 29, pp. 126-137.

Diebold, Francis X. and Robert S. Mariano (1995) "Comparing Predictive Accuracy," Journal of Business 8 Economic Statistics, Vol. 13, pp. 253-263.

Faust, Jon, Eric T. Swanson, and Jonathan H. Wright (2004a) "Do Federal Reserve Policy Surprises Reveal Superior Information about the Economy?" Contributions to Macroeconomics, Vol. 4.

Faust, Jon, Eric T. Swanson, and Jonathan H. Wright (2004b) "Identifying VARs Based on High Frequency Futures Data," Journal of Monetary Economics, Vol. 51, pp. 1107-1131. 
Gamber, Edward N and Julie K Smith (2009) "Are the Feds inflation forecasts still superior to the private sectors?" Journal of Macroeconomics, Vol. 31, pp. 240-251.

Gertler, Mark and Peter Karadi (2015) "Monetary Policy Surprises, Credit Costs, and Economic Activity," American Economic Journal: Macroeconomics, Vol. 7, pp. 44-76.

Grossman, Sanford (1981) "An Introduction to the Theory of Rational Expectations under Asymmetric Information," Review of Economic Studies, Vol. 48, pp. 541-559.

Grossman, Sanford (1989) The Informational Role of Prices, Cambridge, MA: MIT Press, 1st edition.

Gürkaynak, Refet S., Brian P. Sack, and Eric T. Swanson (2005a) "The Sensitivity of LongTerm Interest Rates to Economic News: Evidence and Implications for Macroeconomic Models," American Economic Review, Vol. 95, pp. 425-436.

Gürkaynak, Refet S., Brian P. Sack, and Eric T. Swanson (2005b) "Do Actions Speak Louder Than Words? The Response of Asset Prices to Monetary Policy Actions and Statements," International Journal of Central Banking, Vol. 1, pp. 55-93.

Gürkaynak, Refet S., Brian Sack, and Jonathan H. Wright (2007) "The U.S. Treasury Yield Curve: 1961 to the Present," Journal of Monetary Economics, Vol. 54, pp. 2291-2304.

Hanson, Samuel and Jeremy Stein (2015) "Monetary Policy and Long-Term Real Rates," Journal of Financial Economics, Vol. 115, pp. 429-448.

Hayek, Friedrich (1945) "The Use of Knowledge in Society," American Economic Review, Vol. 35, pp. 519-530.

Hoesch, Lukas, Barabara Rossi, and Tatevik Sekhposyan (2020) "Has the Information Channel of Monetary Policy Disappeared? Revisiting the Empirical Evidence," CEPR Discussion Paper, Vol. 14456.

Jarocinski, Marek and Peter Karadi (2020) "Deconstructing Monetary Policy Surprises - The Role of Information Shocks," American Economic Journal: Macroeconomics, Vol. 12, pp. $1-43$.

Karnaukh, Nina (2019) "Growth Forecasts and News about Future Monetary Policy."

Kuttner, Kenneth N. (2001) "Monetary Policy Surprises and Interest Rates: Evidence from the Fed Funds Futures Market," Journal of Monetary Economics, Vol. 47, pp. 523-544.

Lunsford, Kurt (2019) "Policy Language and Information Effects in the Early Days of Federal Reserve Forward Guidance," working paper, Federal Reserve Bank of Cleveland.

Miranda-Agrippino, Silvia (2017) "Unsurprising Shocks: Information, Premia, and the Monetary Transmission," Staff Working Paper 626, Bank of England.

Miranda-Agrippino, Silvia and Giovanni Ricco (2020) "The Transmission of Monetary Policy Shocks," American Economic Journal: Macroeconomics, forthcoming. 
Nakamura, Emi and Jón Steinsson (2018) "High-Frequency Identification of Monetary NonNeutrality: The Information Effect," Quarterly Journal of Economics, Vol. 133, pp. 12831330 .

Paul, Pascal (2019) "The Time-Varying Effect of Monetary Policy on Asset Prices," Review of Economics and Statistics, forthcoming.

Piazzesi, Monika and Eric Swanson (2008) "Futures Prices as Risk-Adjusted Forecasts of Monetary Policy," Journal of Monetary Economics, Vol. 55, pp. 677-691.

Romer, Christina D. and David H. Romer (2000) "Federal Reserve Information and the Behavior of Interest Rates," American Economic Review, Vol. 90, pp. 429-457.

Rudebusch, Glenn (2002) "Term Structure Evidence on Interest Rate Smoothing and Monetary Policy Inertia," Journal of Monetary Economics, Vol. 49, pp. 1161-1187.

Sack, Brian and Volker Wieland (2000) "Interest-Rate Smoothing and Optimal Monetary Policy: A Review of Recent Empirical Evidence," Journal of Economics and Business, Vol. 52, pp. 205-228.

Sargent, Thomas J. and Neil Wallace (1975) "'Rational" Expectations, the Optimal Monetary Instrument, and the Optimal Money Supply Rule," Journal of Political Economy, Vol. 83, pp. 241-254.

Sims, Christopher A (2002) "The Role of Models and Probabilities in the Monetary Policy Process," Brookings Papers on Economic Activity, Vol. 2002, pp. 1-40.

Stock, James and Mark Watson (2012) "Disentangling the Channels of the 2007-09 Recession," Brookings Papers on Economic Activity, Vol. Spring, pp. 81-130.

Swanson, Eric T. (2019) "Measuring the Effects of Federal Reserve Forward Guidance and Asset Purchases on Financial Markets," NBER Working Paper \#23311. 


\section{Appendix}

\section{A Design of Our Survey of Blue Chip Economists}

We sent the following email with our survey questions to the Chief Economists of all 52 professional forecasting firms in the Blue Chip survey panel:

Subject: quick question about how FOMC announcements affect your forecast

Dear [Recipient]:

An important question in Macroeconomics is whether and how FOMC announcements affect private sector economic forecasts. We (Michael Bauer and Eric Swanson) are working on a new research paper that looks at this important question and would be extremely interested to learn how FOMC announcements affect your own group's forecasts of GDP, unemployment, and inflation. We'd be very grateful if you would take a minute to answer the following, very brief one-time survey on this topic:

1. Do you revise any of your macroeconomic forecasts (GDP, unemployment, or inflation) in response to the FOMCs federal funds rate decision? If yes, please briefly explain which forecasts you revise and which direction you revise those forecasts (i.e., do you revise them up or down if the decision is more hawkish/dovish than expected).

2. Do you revise any of your macroeconomic forecasts in response to the $\boldsymbol{F} \boldsymbol{O M C}$ statement? If yes, please briefly explain which forecasts you revise, and which direction you revise those forecasts (i.e., do you revise them up or down if the statement is more hawkish/dovish than expected).

3. Do you revise any of your macroeconomic forecasts in response to the dot plot released by the FOMC in the Summary of Economic Projections (SEP)? If yes, please briefly explain which forecasts you revise and which direction you revise those forecasts (i.e., do you revise them up or down if the dot plot is more hawkish/dovish than expected)

4. Do you revise any of your macroeconomic forecasts in response to $\boldsymbol{S E P}$ forecasts of GDP, unemployment, and inflation in the Summary of Economic Projections? If yes, please briefly explain which FOMC forecasts matter for you, which forecasts you revise, and which direction you revise those forecasts.

Individual responses will be kept confidential, and we will only publish aggregated results. We'd like to emphasize that there are no right or wrong answers to these questionsthere are theoretical reasons why the answers could go in any direction, or no direction. The point of our research is to find out what professional forecasters like yourself do in practice. If you are interested, we'd be happy to send you our overall results and analysis of this topic once we have a draft of our paper. Thank you very much for your time and help on this.

We conducted our survey throughout July and August 2019. If we did not receive an initial response, we followed up with two brief reminder emails, with about 1.5 weeks between each email. In the end, we received 36 responses, for a response rate of about $70 \%$. 
When the initial response was vague regarding the direction in which they revise their forecasts (e.g., just replying "yes" to the questions) we followed up with a brief email asking for clarification on the direction of those revisions, which cleared up the ambiguity. Sometimes, the initial response was a brief "no" to each of the four questions; in these cases, we followed up with a brief email asking for clarification regarding whether they viewed surprise FOMC announcements as having no significant effect on GDP, unemployment, or inflation vs. whether they viewed surprise FOMC announcements as having a significant effect but were just rarely surprised in practice over the past several years. Again, our followup email always resolved the ambiguity.

\section{B Additional Empirical Results}

Tables B.1 and B.2 contain additional results for the information effect regressions in Section 2. Table B.3 shows results for additional regression specifications controlling for economic news, discussed in Section 3. Tables B.4, B.5, and B.6 show additional comparisons of the accuracy of Greenbook and Blue Chip forecasts, discussed in Section 6. 
Table B.1: "Fed Information Effect" Regression Results (White standard errors)

\begin{tabular}{cccc}
\hline & \multicolumn{2}{c}{ (1) Campbell et al. } & (2) Nakamura-Steinsson \\
Blue Chip forecast & $\begin{array}{c}\text { fed funds rate } \\
\text { "target factor" }\end{array}$ & $\begin{array}{c}\text { fwd. guidance } \\
\text { "path factor" }\end{array}$ & $\begin{array}{c}\text { first princip. comp. } \\
\text { of futures rates }\end{array}$ \\
\hline (A) Replication sample: $1 / 1990-6 / 2007$ for Campbell et al., $1 / 1995-3 / 2014$ for NS $(N=129,120)$ \\
unemployment rate & -0.11 & $-0.23^{* *}$ & -0.17 \\
real GDP growth & $(.097)$ & $(.113)$ & $(.267)$ \\
CPI inflation & 0.10 & $0.27^{* *}$ & $0.92^{* * *}$ \\
& $(.118)$ & $(.136)$ & 0.06 \\
& 0.15 & 0.10 & $(.253)$ \\
\hline
\end{tabular}

(B) Full sample: 1/1990-6/2019, including unscheduled announcements $(N=217)$

$\begin{array}{lccc}\text { unemployment rate } & -0.16 & -0.24^{* *} & -0.39^{* *} \\ & (.137) & (.115) & (.196) \\ \text { real GDP growth } & 0.16 & 0.14 & 0.33 \\ & (.184) & (.126) & (.257) \\ \text { CPI inflation } & 0.16^{*} & 0.08 & 0.29^{* *} \\ & (.096) & (.120) & (.143)\end{array}$

(C) Full sample: 1/1990-6/2019, excluding unscheduled announcements $(N=206)$

$\begin{array}{lccc}\text { unemployment rate } & 0.07 & -0.32^{* *} & -0.30 \\ & (.268) & (.125) & (.313) \\ \text { real GDP growth } & 0.13 & 0.37^{* *} & 0.54 \\ & (.301) & (.144) & (.356) \\ \text { CPI inflation } & 0.12 & 0.13 & 0.27 \\ & (.156) & (.128) & (.198)\end{array}$

(D) Full sample: 1/1990-6/2019, excl. unsched. announcements and 7/2008-6/2009 $(N=198)$

$\begin{array}{lccc}\text { unemployment rate } & -0.02 & -0.20^{* *} & -0.25 \\ & (.159) & (.096) & (.176) \\ \text { real GDP growth } & 0.29^{*} & 0.32^{* * *} & 0.64^{* * *} \\ & (.178) & (.124) & (.219) \\ \text { CPI inflation } & 0.15 & 0.06 & 0.20 \\ & (.130) & (.141) & (.184)\end{array}$

Same as Table 1, except that asymptotic heteroskedasticity-consistent (White) standard errors are reported rather than bootstrapped standard errors. See notes to Table 1 for details. 
Table B.2: "Fed Information Effect" Regression Results (1994-2019)

\begin{tabular}{cccc}
\hline & \multicolumn{2}{c}{ (1) Campbell et al. } & (2) Nakamura-Steinsson \\
fed funds rate & fwd. guidance \\
"target factor" & "path factor" & $\begin{array}{c}\text { first princip. comp. } \\
\text { of futures rates }\end{array}$ \\
\hline Blue Chip forecast & 0.02 & $-0.24^{*}$ & -0.17 \\
unemployment rate & $(.109)$ & $(.135)$ & $(.288)$ \\
real GDP growth & 0.32 & $0.37^{* *}$ & $0.92^{* *}$ \\
CPI inflation & $(.138)$ & $(.169)$ & $(.368)$ \\
& 0.11 & 0.12 & 0.06 \\
& $(.115)$ & $(.142)$ & $(.253)$ \\
\hline
\end{tabular}

(B) Full sample: 1/1994-6/2019, including unscheduled announcements $(N=182)$

$\begin{array}{lccc}\text { unemployment rate } & -0.07 & -0.26^{* *} & -0.32 \\ & (.133) & (.159) & (.231) \\ \text { real GDP growth } & 0.29 & 0.24 & 0.62^{*} \\ & (.182) & (.220) & (.330) \\ \text { CPI inflation } & 0.11 & 0.12 & 0.26 \\ & (.106) & (.125) & (.227)\end{array}$

(C) Full sample: 1/1994-6/2019, excluding unscheduled announcements $(N=179)$

$\begin{array}{lccc}\text { unemployment rate } & 0.14 & -0.35^{* *} & -0.28 \\ & (.198) & (.159) & (.264) \\ \text { real GDP growth } & 0.14 & 0.40^{* *} & 0.60 \\ & (.246) & (.199) & (.353) \\ \text { CPI inflation } & 0.11 & 0.15 & 0.27 \\ & (.153) & (.123) & (.286)\end{array}$

(D) Full sample: 1/1994-6/2019, excl. unsched. announcements and 7/2008-6/2009 $(N=171)$

$\begin{array}{lccc}\text { unemployment rate } & 0.05 & -0.23^{*} & -0.23 \\ & (.162) & (.132) & (.213) \\ \text { real GDP growth } & 0.33^{*} & 0.36^{* *} & 0.71^{* * *} \\ & (.200) & (.179) & (.258) \\ \text { CPI inflation } & 0.14 & 0.07 & 0.20 \\ & (.138) & (.112) & (.186)\end{array}$

Same as Table 1 except that samples begin in February 1994 rather than January 1990. Bootstrapped standard errors in parentheses. See notes to Table 1 for details. 
Table B.3: Economic News Drives Out the "Fed Information Effect" (excluding Brave et al. index from news)

\begin{tabular}{|c|c|c|c|}
\hline & (1) Camp & eell et al. & (2) Nakamura-Steinsson \\
\hline Blue Chip forecast & $\begin{array}{l}\text { fed funds rate } \\
\text { "target factor" }\end{array}$ & $\begin{array}{l}\text { fwd. guidance } \\
\text { "path factor" }\end{array}$ & $\begin{array}{l}\text { first princip. comp. } \\
\text { "MP surprise" }\end{array}$ \\
\hline ) Replication sample: $1 /$ & 2007 for Camp & ell et al., $1 / 19$ & $3 / 2014$ for $\mathrm{NS}(N=129$ \\
\hline Unemployment rate & $\begin{array}{c}.028 \\
(.098)\end{array}$ & $\begin{array}{c}-.115 \\
(.137)\end{array}$ & $\begin{array}{l}.147 \\
(.268)\end{array}$ \\
\hline Real GDP growth & $\begin{array}{l}.019 \\
(.179)\end{array}$ & $\begin{array}{l}.003 \\
(.365)\end{array}$ & $\begin{array}{l}.618^{*} \\
(.321)\end{array}$ \\
\hline B) Full sample: 1/1990-6 & acluding unsche & duled announce & $\operatorname{nts}(N=217)$ \\
\hline Unemployment rate & $\begin{array}{l}.087 \\
(.097)\end{array}$ & $\begin{array}{l}-.010 \\
(.127)\end{array}$ & $\begin{array}{l}.117 \\
(.170)\end{array}$ \\
\hline Real GDP growth & $\begin{array}{r}-.089 \\
(.155)\end{array}$ & $\begin{array}{l}-.211 \\
(.202)\end{array}$ & $\begin{array}{r}-.270 \\
(.269)\end{array}$ \\
\hline C) Full sample: 1/1990-6 & xcluding unsche & duled announce & $\operatorname{nts}(N=206)$ \\
\hline Unemployment rate & $\begin{array}{l}.312^{* *} \\
(.152)\end{array}$ & $\begin{array}{l}.002 \\
(.134)\end{array}$ & $\begin{array}{l}.306 \\
(.215)\end{array}$ \\
\hline Real GDP growth & $\begin{array}{r}-.058 \\
(.209)\end{array}$ & $\begin{array}{c}-.114 \\
(.182)\end{array}$ & $\begin{array}{r}-.182 \\
(.292)\end{array}$ \\
\hline D) Full sample: 1/1990-6 & xcl. unsched. a & nouncements a & $7 / 2008-6 / 2009(N=198)$ \\
\hline Unemployment rate & $\begin{array}{l}.076 \\
(.139)\end{array}$ & $\begin{array}{r}-0.076 \\
(.118)\end{array}$ & $\begin{array}{c}-.021 \\
(.188)\end{array}$ \\
\hline Real GDP growth & $\begin{array}{l}.261 \\
(.179)\end{array}$ & $\begin{array}{l}.081 \\
(.154)\end{array}$ & $\begin{array}{l}.326 \\
(.248)\end{array}$ \\
\hline
\end{tabular}

Same as Table 4 except that the variable $n e w s_{t}$ excludes the Brave et al. (2019) index. See notes to Table 4 for details. 
Table B.4: Comparison of Greenbook and Blue Chip Forecasts, 1980-2013

\begin{tabular}{|c|c|c|c|c|c|c|c|}
\hline \multirow{2}{*}{$\begin{array}{c}\text { Horizon } \\
\text { (quarters) }\end{array}$} & \multicolumn{3}{|c|}{ RMSEs } & \multicolumn{4}{|c|}{ Encompassing regressions } \\
\hline & GB & $\mathrm{BC}$ & $H_{0}: G B=B C$ & GB & $\mathrm{BC}$ & $R^{2}$ & $H_{0}: G B=B C$ \\
\hline \multicolumn{8}{|c|}{ (A) Unemployment rate } \\
\hline 0 & 0.20 & 0.22 & .280 & $\begin{array}{l}0.65^{* * *} \\
(.117)\end{array}$ & $\begin{array}{l}0.34^{* * *} \\
(.117)\end{array}$ & .99 & .194 \\
\hline 1 & 0.39 & 0.41 & .322 & $\begin{array}{l}0.77^{* * *} \\
(.209)\end{array}$ & $\begin{array}{c}0.21 \\
(.213)\end{array}$ & .95 & .190 \\
\hline 2 & 0.59 & 0.61 & .660 & $\begin{array}{c}0.74^{* *} \\
(.320)\end{array}$ & $\begin{array}{c}0.23 \\
(.312)\end{array}$ & .88 & .417 \\
\hline 3 & 0.76 & 0.79 & .644 & $\begin{array}{c}0.81^{*} \\
(.414)\end{array}$ & $\begin{array}{c}0.13 \\
(.404)\end{array}$ & .79 & .404 \\
\hline 0-3 avg. & 0.46 & 0.47 & .539 & $\begin{array}{l}0.79^{* * *} \\
(.282)\end{array}$ & $\begin{array}{c}0.18 \\
(.276)\end{array}$ & .93 & .276 \\
\hline \multicolumn{8}{|c|}{ (B) Real GDP growth } \\
\hline 0 & 2.17 & 2.32 & .032 & $\begin{array}{l}1.07^{* * *} \\
(.249)\end{array}$ & $\begin{array}{c}-0.10 \\
(.348)\end{array}$ & .50 & .047 \\
\hline 1 & 2.94 & 2.80 & .247 & $\begin{array}{c}-0.09 \\
(.515)\end{array}$ & $\begin{array}{c}1.09^{*} \\
(.619)\end{array}$ & .19 & .284 \\
\hline 2 & 2.87 & 2.89 & .931 & $\begin{array}{c}0.64 \\
(.495)\end{array}$ & $\begin{array}{c}-0.20 \\
(.854)\end{array}$ & .07 & .508 \\
\hline 3 & 2.98 & 2.89 & .681 & $\begin{array}{c}0.18 \\
(.514)\end{array}$ & $\begin{array}{c}-0.19 \\
(.882)\end{array}$ & .00 & .769 \\
\hline 0-3 avg. & 1.83 & 1.78 & .675 & $\begin{array}{c}0.38 \\
(.531)\end{array}$ & $\begin{array}{c}0.55 \\
(.724)\end{array}$ & .27 & .892 \\
\hline \multicolumn{8}{|c|}{ (C) CPI inflation } \\
\hline 0 & 1.10 & 1.40 & .102 & $\begin{array}{l}0.98^{* * *} \\
(.106)\end{array}$ & $\begin{array}{c}-0.11 \\
(.098)\end{array}$ & .86 & .000 \\
\hline 1 & 2.21 & 2.15 & .580 & $\begin{array}{l}0.73^{* * *} \\
(.250)\end{array}$ & $\begin{array}{c}-0.06 \\
(.314)\end{array}$ & .46 & .160 \\
\hline 2 & 2.07 & 1.94 & .123 & $\begin{array}{c}0.16 \\
(.236)\end{array}$ & $\begin{array}{c}0.58 \\
(.352)\end{array}$ & .37 & .468 \\
\hline 3 & 2.02 & 2.04 & .841 & $\begin{array}{c}0.64^{*} \\
(.345)\end{array}$ & $\begin{array}{c}0.12 \\
(.463)\end{array}$ & .36 & .517 \\
\hline 0-3 avg. & 1.21 & 1.20 & .884 & $\begin{array}{l}0.89^{* * *} \\
(.245)\end{array}$ & $\begin{array}{c}-0.16 \\
(.270)\end{array}$ & .73 & .038 \\
\hline
\end{tabular}

Same as Table 9 except sample runs from 1980-2013 (274 observations). See notes to Table 9 for details. 
Table B.5: Comparison of Greenbook and Blue Chip Forecasts, Blue Chip always after Greenbook

\begin{tabular}{|c|c|c|c|c|c|c|c|}
\hline \multirow{2}{*}{$\begin{array}{c}\text { Horizon } \\
\text { (quarters) }\end{array}$} & \multicolumn{3}{|c|}{ RMSEs } & \multicolumn{4}{|c|}{ Encompassing regressions } \\
\hline & GB & $\mathrm{BC}$ & $H_{0}: G B=B C$ & GB & $\mathrm{BC}$ & $R^{2}$ & $H_{0}: G B=B C$ \\
\hline \multicolumn{8}{|c|}{ (A) Unemployment rate } \\
\hline 0 & 0.25 & 0.23 & .097 & $\begin{array}{c}0.26 \\
(.169)\end{array}$ & $\begin{array}{l}0.73^{* * *} \\
(.172)\end{array}$ & .98 & .166 \\
\hline 1 & 0.44 & 0.42 & .235 & $\begin{array}{c}0.15 \\
(.338)\end{array}$ & $\begin{array}{l}0.84^{*} \\
(.345)\end{array}$ & .94 & .318 \\
\hline 2 & 0.63 & 0.61 & .535 & $\begin{array}{c}0.30 \\
(.469)\end{array}$ & $\begin{array}{c}0.68 \\
(.467)\end{array}$ & .87 & .685 \\
\hline 3 & 0.81 & 0.80 & .919 & $\begin{array}{c}0.53 \\
(.559)\end{array}$ & $\begin{array}{c}0.41 \\
(.548)\end{array}$ & .77 & .915 \\
\hline $0-3$ avg. & 0.50 & 0.48 & .490 & $\begin{array}{c}0.30 \\
(.462)\end{array}$ & $\begin{array}{c}0.67 \\
(.459)\end{array}$ & .91 & .688 \\
\hline \multicolumn{8}{|c|}{ (B) Real GDP growth } \\
\hline 0 & 2.50 & 2.44 & .405 & $\begin{array}{c}0.20 \\
(.333)\end{array}$ & $\begin{array}{c}0.85^{* *} \\
(.408)\end{array}$ & .39 & .369 \\
\hline 1 & 2.81 & 2.69 & .174 & $\begin{array}{c}-0.04 \\
(.397)\end{array}$ & $\begin{array}{l}0.95^{* *} \\
(.475)\end{array}$ & .16 & .235 \\
\hline 2 & 2.99 & 2.93 & .736 & $\begin{array}{c}0.37 \\
(.517)\end{array}$ & $\begin{array}{c}-0.04 \\
(.845)\end{array}$ & .02 & .749 \\
\hline 3 & 3.00 & 2.96 & .871 & $\begin{array}{c}0.30 \\
(.551)\end{array}$ & $\begin{array}{c}-0.26 \\
(.879)\end{array}$ & .01 & .667 \\
\hline $0-3$ avg. & 1.88 & 1.80 & .512 & $\begin{array}{c}0.24 \\
(.555)\end{array}$ & $\begin{array}{c}0.65 \\
(.752)\end{array}$ & .23 & .743 \\
\hline \multicolumn{8}{|c|}{ (C) CPI inflation } \\
\hline 0 & 1.43 & 1.54 & .478 & $\begin{array}{l}0.77^{* * *} \\
(.159)\end{array}$ & $\begin{array}{c}0.11 \\
(.152)\end{array}$ & .77 & .030 \\
\hline 1 & 2.23 & 2.03 & .038 & $\begin{array}{c}0.31 \\
(.302)\end{array}$ & $\begin{array}{c}0.42 \\
(.422)\end{array}$ & .41 & .872 \\
\hline 2 & 2.10 & 2.00 & .140 & $\begin{array}{c}0.00 \\
(.321)\end{array}$ & $\begin{array}{c}0.81^{*} \\
(.456)\end{array}$ & .37 & .292 \\
\hline 3 & 2.06 & 2.09 & .719 & $\begin{array}{c}0.64 \\
(.389)\end{array}$ & $\begin{array}{c}0.12 \\
(.504)\end{array}$ & .34 & .555 \\
\hline 0-3 avg. & 1.25 & 1.19 & .520 & $\begin{array}{r}0.60^{*} \\
(.336)\end{array}$ & $\begin{array}{c}0.18 \\
(.353)\end{array}$ & .70 & .535 \\
\hline
\end{tabular}

Same as Table B.4, except that BC forecasts are always after the GB forecast, giving BC an informational advantage over GB. Sample runs from 1980-2013 (274 observations). See notes to Table 9 for details. 
Table B.6: Comparison of Greenbook and Blue Chip Forecasts, Blue Chip always before Greenbook

\begin{tabular}{|c|c|c|c|c|c|c|c|}
\hline \multirow{2}{*}{$\begin{array}{l}\text { Horizon } \\
\text { (quarters) }\end{array}$} & \multicolumn{3}{|c|}{ RMSEs } & \multicolumn{4}{|c|}{ Encompassing regressions } \\
\hline & GB & $\mathrm{BC}$ & $H_{0}: G B=B C$ & GB & $\mathrm{BC}$ & $R^{2}$ & $H_{0}: G B=B C$ \\
\hline \multicolumn{8}{|c|}{ (A) Unemployment rate } \\
\hline 0 & 0.17 & 0.21 & .002 & $\begin{array}{l}0.82^{* * *} \\
(.105)\end{array}$ & $\begin{array}{c}0.16 \\
(.105)\end{array}$ & .99 & .002 \\
\hline 1 & 0.35 & 0.41 & .005 & $\begin{array}{l}1.07^{* * *} \\
(.158)\end{array}$ & $\begin{array}{c}-0.11 \\
(.162)\end{array}$ & .96 & .000 \\
\hline 2 & 0.55 & 0.60 & .153 & $\begin{array}{l}1.02^{* * *} \\
(.212)\end{array}$ & $\begin{array}{c}-0.07 \\
(.207)\end{array}$ & .90 & .009 \\
\hline 3 & 0.73 & 0.80 & .266 & $\begin{array}{l}1.06^{* * *} \\
(.291)\end{array}$ & $\begin{array}{c}-0.14 \\
(.277)\end{array}$ & .81 & .034 \\
\hline 0-3 avg. & 0.42 & 0.47 & .064 & $\begin{array}{l}1.09^{* * *} \\
(.175)\end{array}$ & $\begin{array}{c}-0.14 \\
(.173)\end{array}$ & .94 & .000 \\
\hline \multicolumn{8}{|c|}{ (B) Real GDP growth } \\
\hline 0 & 2.10 & 2.35 & .004 & $\begin{array}{l}1.23^{* * *} \\
(.158)\end{array}$ & $\begin{array}{c}-0.33 \\
(.221)\end{array}$ & .55 & .000 \\
\hline 1 & 2.82 & 2.75 & .578 & $\begin{array}{c}0.33 \\
(.387)\end{array}$ & $\begin{array}{c}0.62 \\
(.466)\end{array}$ & .19 & .715 \\
\hline 2 & 2.88 & 2.89 & .941 & $\begin{array}{c}0.63 \\
(.430)\end{array}$ & $\begin{array}{c}-0.19 \\
(.795)\end{array}$ & .07 & .479 \\
\hline 3 & 3.00 & 2.91 & .694 & $\begin{array}{c}0.21 \\
(.471)\end{array}$ & $\begin{array}{c}-0.10 \\
(.805)\end{array}$ & .01 & .783 \\
\hline 0-3 avg. & 1.77 & 1.74 & .792 & $\begin{array}{c}0.50 \\
(.387) \\
\end{array}$ & $\begin{array}{c}0.41 \\
(.550)\end{array}$ & .29 & .918 \\
\hline \multicolumn{8}{|c|}{ (C) CPI inflation } \\
\hline 0 & 0.95 & 1.30 & .022 & $\begin{array}{l}1.01^{* * *} \\
(.134)\end{array}$ & $\begin{array}{c}-0.13 \\
(.136)\end{array}$ & .89 & .000 \\
\hline 1 & 1.97 & 1.95 & .897 & $\begin{array}{l}0.77^{* * *} \\
(.254)\end{array}$ & $\begin{array}{c}-0.11 \\
(.298)\end{array}$ & .51 & .107 \\
\hline 2 & 2.18 & 2.03 & .070 & $\begin{array}{c}0.01 \\
(.306)\end{array}$ & $\begin{array}{c}0.78^{* *} \\
(.395)\end{array}$ & .36 & .264 \\
\hline 3 & 2.08 & 2.07 & .926 & $\begin{array}{c}0.35 \\
(.445)\end{array}$ & $\begin{array}{c}0.40 \\
(.588)\end{array}$ & .33 & .958 \\
\hline 0-3 avg. & 1.16 & 1.12 & .617 & $\begin{array}{l}0.70^{* * *} \\
(.210)\end{array}$ & $\begin{array}{c}0.06 \\
(.268)\end{array}$ & .74 & .171 \\
\hline
\end{tabular}

Same as Table B.4, except that BC forecasts are always before the GB forecast, giving GB an informational advantage over BC. Sample runs from 1980-2013 (274 observations). See notes to Table 9 for details. 


\title{
IMFS WORKING PAPER SERIES
}

\author{
Recent Issues
}

154 / $2021 \quad$ Alexander Meyer-Gohde

$153 / 2021$

152 / 2021

$151 / 2021$

$150 / 2021$

149 / 2021

$148 / 2021$

147 / 2021

$146 / 2021$

$145 / 2020$

144 / 2020

$143 / 2020$

$142 / 2020$

$141 / 2020$
Gregor Boehl

Philipp Lieberknecht

Lazar Milivojevic

Balint Tatar

Thomas Jost

Franz Seitz

Gerhard Rösl

Franz Seitz

Wolfgang Lechthaler

Mewael F. Tesfaselassie

Gregor Boehl

Brian Fabo

Martina Jančoková

Elisabeth Kempf

Luboš Pástor

Robert C.M. Beyer

Lazar Milivojevic

Lars P. Feld

Volker Wieland

Mátyás Farkas

Balint Tatar

Gregor Boehl

Felix Strobel

Gregor Boehl

Gavin Goy

Felix Strobel

Karl-Heinz Tödter
On the Accuracy of Linear DSGE Solution Methods and the Consequences for LogNormal Asset Pricing

The Hockey Stick Phillips Curve and the Zero Lower Bound

Fixed exchange rate - a friend or foe of labor cost adjustments?

Designing a European Monetary Fund: What role for the IMF?

Cash and Crises: No surprises by the virus

Endogenous Growth, Skill Obsolescence and Output Hysteresis in a New

Keynesian Model with Unemployment

Efficient Solution and Computation of Models with Occasionally Binding Constraints

Fifty Shades of QE: Conflicts of Interest in Economic Research

Dynamics and Synchronization of Global Equilibrium Interest Rates

The German Federal Constitutional Court Ruling and the European Central Bank's Strategy

Bayesian Estimation of DSGE Models with Hamiltonian Monte Carlo

U.S. Business Cycle Dynamics at the Zero Lower Bound

A Structural Investigation of Quantitative Easing

Ein SIRD-Modell zur Infektionsdynamik mit endogener Behandlungskapazität und Lehren für Corona-Statistiken 
$\begin{array}{ll}140 / 2020 & \begin{array}{l}\text { Helmut Siekmann } \\ \text { Volker Wieland }\end{array}\end{array}$

139 / $2020 \quad$ Volker Wieland

$138 / 2020$

$137 / 2019$

$136 / 2019$

$135 / 2019$

$133 / 2019$

$132 / 2019$

$131 / 2019$

$130 / 2019$

$129 / 2018$

$128 / 2018$

$127 / 2018$

$125 / 2018$
Francisco Gomes

Michael Haliassos

Tarun Ramadorai

Martin Kliem

Alexander Meyer-Gohde

Luc Arrondel

Hector Calvo-Pardo

Chryssi Giannitsarou

Michael Haliassos

Tiziana Assenza

Alberto Cardaci

Domenico Delli Gatti

Helmut Siekmann

Josefine Quast

Maik Wolters

Galina Potjagailo

Maik Wolters

Philipp Lieberknecht

Volker Wieland

Eduard Hofert

Olga Goldfayn-Frank

Johannes Wohlfart

Christopher Roth

Johannes Wohlfart

Michael Haliassos

Thomas Jansson

Yigitcan Karabulut

Felix Strobel

Alexander Meyer-Gohde

Daniel Neuhoff
The Ruling of the Federal Constitutional Court concerning the Public Sector Purchase Program: A Practical Way Forward

Verfahren zum Anleihekaufprogramm der EZB

Household Finance

(Un)expected Monetary Policy Shocks and Term Premia

Informative Social Interactions

Perceived wealth, cognitive sophistication and behavioral inattention

The Asset Purchase Programmes of the ESCB - an interdisciplinary evaluation

Reliable Real-time Output Gap Estimates Based on a Modified Hamilton Filter

Global Financial Cycles since 1880

On the Macroeconomic and Fiscal Effects of the Tax Cuts and Jobs Act

Regulating Virtual Currencies

How Do Consumers Adapt to a New

Environment in their Economic

Forecasting? Evidence from the German

Reunification

How Do Expectations About the

Macroeconomy Affect Personal

Expectations and Behavior?

Financial Literacy Externalities

The Government Spending Multiplier, Fiscal Stress and the Zero Lower Bound

Generalized Exogenous Processes in DSGE: A Bayesian Approach 